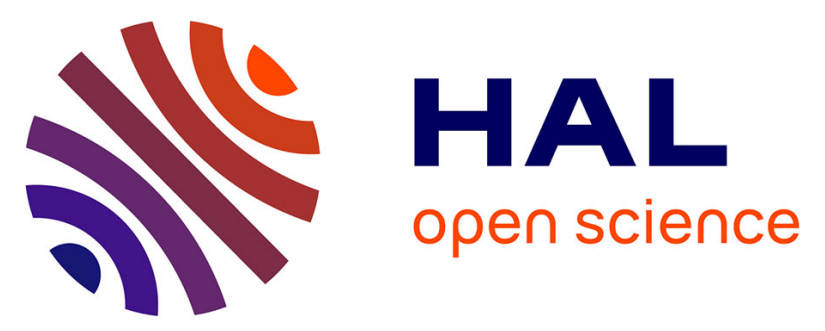

\title{
Electrified District Heating Networks: A Thermo-Economic Optimisation Based on Exergy and Energy Analyses
}

Getnet Tadesse Ayele, Mohamed Tahar Mabrouk, Pierrick Haurant, Björn Laumert, Bruno Lacarrière, Massimo Santarelli

\section{To cite this version:}

Getnet Tadesse Ayele, Mohamed Tahar Mabrouk, Pierrick Haurant, Björn Laumert, Bruno Lacarrière, et al.. Electrified District Heating Networks: A Thermo-Economic Optimisation Based on Exergy and Energy Analyses. International Journal of Exergy, 2021, 35 (1), 10.1504/IJEX.2021.115088 . hal03214522

\section{HAL Id: hal-03214522 \\ https://hal.science/hal-03214522}

Submitted on 1 May 2021

HAL is a multi-disciplinary open access archive for the deposit and dissemination of scientific research documents, whether they are published or not. The documents may come from teaching and research institutions in France or abroad, or from public or private research centers.
L'archive ouverte pluridisciplinaire HAL, est destinée au dépôt et à la diffusion de documents scientifiques de niveau recherche, publiés ou non, émanant des établissements d'enseignement et de recherche français ou étrangers, des laboratoires publics ou privés. 


\title{
Electrified District Heating Networks: A Thermo-Economic Optimisation Based on Exergy and Energy Analyses
}

\author{
Getnet Tadesse Ayele ${ }^{1,2, *}$, Mohamed Tahar Mabrouk ${ }^{1}$, Pierrick Haurant ${ }^{1}$, Björn Laumert ${ }^{2}$, Bruno Lacarrière ${ }^{1}$, Massimo Santarelli ${ }^{3}$ \\ (gtayele@kth.se, mohamed-tahar.mabrouk@imt-atlantique.fr, pierrick.haurant@imt-atlantique.fr, bjorn.laumert@energy.kth.se, \\ bruno.lacarriere@imt-atlantique.fr, massimo.santarelli@polito.it )
}

Getnet Tadesse Ayele (male) earned a Joint Master's Degree in Sustainable Electrical Power System from University of Oviedo, University of Nottingham, Polytechnic of Coimbra and Sapienza University of Rome in 2015. He is currently a PhD candidate in the SELECT+ Erasmus Mundus double degree PhD programme hosted between IMT Atlantique, Nantes, France and KTH Royal Institute of Technology, Stockholm, Sweden. His research interest is on multi-energy system modelling, simulation and optimisation, and renewables integration.

Mohamed-Tahar Mabrouk (male): holds a Ph.D degree in Energy Engineering from University of Lorraine, France. He is currently an Associate Professor at the Department of Energy Systems and Environment in IMT Atlantique, a leading Technological University in France. His main research interest is on Energy systems modelling, simulation and optimisation.

Pierrick Haurant (male) held his PhD in Energy Engineering at University Pasquale Paoli of Corsica in 2012. $\mathrm{He}$ is an Associate Professor in the Energy and Environment department at IMT-Atlantique and belongs to GEPEA laboratory since 2016. His main research activities are linked to energy resources, conversion systems, network modelling and optimisation.

Björn Laumert (male), MSc in Chemical Engineering and Engineering Physics, Ph.D. in Energy Technology, Professor in Energy Technology at Department of Energy Technology, KTH, Royal Institute of Technology, Sweden. 10 years of industrial experience as design leader of ESA Ariane Space projects at Volvo Aero Corporation. Today head of the Energy Technology Department at KTH comprising around 100 faculty members and graduate students. Author of around 110 papers in international journals and conferences. The main research activity is linked to the topics of turbomachinery, concentrating solar power and energy infrastructures in cities and regions.

Bruno Lacarrière (male): MSc in Mechanical Engineering, Ph.D. in Energy, Full Professor in the Department Energy Systems and Environment at IMT Atlantique, France. Research activity focuses on local energy solutions using decentralized production and local energy networks supported by ICTs. Author of more than 70 papers in international journals and conferences. Expert of the ETIP-SNET (European Technology \& Innovation Platforms - Smart Networks for Energy Transition) working group and for the International Energy Agency Technology Collaboration Programme IEA-DHC. Involved in different European projects (ESAM, mySMARTLife, ME3, SELECT+). Holder of an industrial chair on Energy \& Data (chair ValaDoE).

Massimo Santarelli (male): Mechanical Engineer, Ph.D. in Thermodynamics and Heat Transfer, Full Professor in Thermodynamics and Heat Transfer, Department of Energy, Politecnico di Torino. Author of around 250 papers in international journals and conferences. The main research activity is linked to the topic of complex innovative systems (thermo-chemical and electro-chemical processes) applied to the energy sector. Coordinator of the STEPS laboratory and of the $\mathrm{CO}_{2}$ Circle Lab of Politecnico di Torino. Coordinator of EU Projects (SOFCOM, DEMOSOFC and REMOTE). Partner in EU projects (NewSOC, ICO2CHEM, WASTE2WATTS, SUBLIME, COMSOS, TEACHY, ENEFIELD, ENFICA-FC, BRISK II, SELECT-CD, Explore Energy, Virtual Hub, MARS-EV).

${ }^{1}$ IMT Atlantique, Department of Energy Systems and Environment, GEPEA, F-44307 Nantes

${ }^{2}$ Department of Energy Technology, KTH Royal Institute of Technology, 10044 Stockholm, Sweden

${ }^{3}$ Dipartimento di Energetica, Politecnico di Torino, Corso Duca degli Abruzzi 24, 10129 Torino, Italy

* Corresponding author (email address: gtayele@kth.se (G.T. Ayele)) 


\begin{abstract}
This paper presents a thermo-economic optimisation of an electrified district heating network consisting of wind power plant, gas-fired combined heat and power plant and heat pumps. The load flow problem of the resulting multi-energy system is formulated by considering all physical and operating parameters in both of the electricity and heat distribution networks. First, energy and exergy analyses are applied to identify and isolate lossy branches of a meshed heating network. This is followed by the optimal placement of heat pumps. Finally, supply and return temperatures are optimised. Particle Swarm Optimisation technique is implemented in order to find the best place of heat pumps, their economical dispatch and optimal temperature profile of the district heating network. Results show that up to $59.12 \%$ of the distribution heat loss and $9.37 \%$ of the operating cost can be saved by following a step-by-step methodology discussed in this paper.
\end{abstract}

Key Words: Combined heat and power (CHP) plants, District heating network (DHN), Electrified district heating network, Energy hubs, Exergy, Heat pumps, Lossy branch identification, Multienergy systems, Optimal placement, Particle swarm optimisation, Thermo-economic optimisation.

\title{
1. Introduction
}

As the global warming effects are pressing more from time to time, decarbonisation of the energy sector through the integration of renewable energy sources became to be a sustainable alternative. Heating and cooling sector is getting more attention recently in that regard. More than half of the energy consumption in European Union (EU) is used for heating and cooling purposes (European Commission, 2015). Only 19.5\% of this demand is covered by renewables in 2017 though countries like Sweden attained 69.1\% (Eurostat, 2018). The experience of Sweden and Finland shows that combined heat and power (CHP) plants and heat pumps (HPs) are key technologies in order to decarbonise the heating and cooling sector (Kontu et al., 2019; Levihn, 2017; Werner, 2017). HPs are also found to be the best technologies in decarbonising large cities' heating system in China for a year 2030 (Zhang et al., 2019). CHPs and HPs are also mentioned as key technologies to enable the $4^{\text {th }}$ generation district heating integration (Lund et al., 2014).

Integration of renewables and co-generation plants alone does not result into an efficient district heating network (DHN). Their dispatch should be optimised in order to minimize distribution losses and the overall operational cost of a given DHN. The temperature levels and the mass flows determine the amount of heat injected into the network from the sources, the distribution loss and the amount of heat consumed at the consumers (Frederiksen and Werner, 2013). For a given heat demand, a higher source temperature results in a higher temperature difference with respect to the surrounding environment. It also means a lower mass flow rate with longer residence time inside pipes. This results in a higher distribution loss, but a lower pumping energy requirement (Bergman et al., 2011).

From exergy point of view, a higher temperature means a higher quality of heat (Bejan et al., 1996). On the other hand, district heating networks are designed mainly to harness low-grade heat from cheap sources (characterized by lower temperature) and distribute it to the end users (Frederiksen and Werner, 2013). Hence, operating these networks at lower temperature makes them more effective from the source temperature level point of view. As a lower supply temperature means a higher mass flow rate and, as a result, a shorter residence time in the pipe, it decreases the heat that could be lost in the network. However, higher mass flows in the pipes need higher pumping energy for circulation. The circulating pumps use electricity which is regarded as a very high quality, also referred to as a pure exergy (Bejan et al., 1996; Dincer and Rosen, 2013). The trade-off between temperature levels, distribution loss and the pumping energy, therefore, needs to be optimised.

Exergy analysis, which considers both quantity and quality of energy, can be used to optimize thermal systems (Dincer and Rosen, 2013). Meshed DHNs are one of such systems where exergy analysis 
can be applied to identify lossy branches and nodes. Many literatures focused on the exergy analysis of the heat source power plants such as waste-based multi-generation plant (Ratlamwala et al., 2019), combined heating, cooling and power plants (Wang et al., 2016; Yao et al., 2016), steam power plants (Tontu et al., 2018), gas-fired combi boiler (Caliskan, 2014) and biomass boiler (Compton et al., 2018). Exergy destruction analysis in a waste recovery heat exchangers is reported in (Wang and Wu, 2017). Exergy analysis of heat pumps is discussed in (Dincer and Rosen, 2013) and (Bilgen and Takahashi, 2002).

On the other hand, there are only limited exergy related researches conducted on heat distribution networks. (Curti et al., 2000) used exergy analysis to optimize emissions from a district heating system. Only the emissions from the power plants are considered in their study. The exergy destruction in the distribution networks are not taken into account.

Terehovics et al., (2017) applied exergy factor to identify the most influential component of a district heating network. Their results show that the exergy factor increases with the supply temperature . Li and Svendsen (2012) used both energy and exergy analysis to study the performance of low temperature district heating networks in comparison to medium and high temperature district heating networks. They found that low temperature district heating networks have lower exergy and energy losses.

Coss et al. (2017), on the other hand, used unit exergy cost of each node in a radial heat distribution network to assess their performance. Only supply pipe networks are considered in their analysis. The exergy loss on the return pipe network and the exergy requirement due to circulation pumps are not dealt in detail.

A thermodynamic analysis of a geothermal district heating system showed that a correlation exists between capital cost of the plants and the associated exergy loss (Ozgener et al., 2005). Similar study is presented in (Coskun et al., 2010) with additional energy and exergy renewability factors. Pompei et al., (2019) applied combination of energy and exergy analysis to evaluate the performance of a solar-assisted DHN. However, the exergy destruction in the distribution network, both on the supply and return sides of the DHN, are not well addressed in all the papers. Neither topology optimisation is considered.

Once the critical and lossy components are identified using energy/exergy analysis, it is usually followed by optimisation of operational parameters. Both mathematical and heuristic/metaheuristic approaches of optimizing energy systems are reported in literature. The level of optimisation can be categorized into two: those at feasibility level and those at operational level. For example, HOMER (HOMER Energy, n.d.) and RETScreen (Natural Resources Canada, 2010) can be used for size optimisation of hybrid energy systems at feasibility level. The details of network topology and operational parameters are not considered in such tools. Because of that the results may become technically infeasible. On the other hand, tools like PowerWorld (PowerWorld, n.d.), consider operational network parameters to solve the economical dispatch and optimal power flow of electrical power systems. TRNSYS is used for thermo-economic optimisation of solar district heating plants (Tian et al., 2018) and secondary distribution network of a low temperature DHN (Park et al., 2017). There are no tools, however, that can handle both electricity and heating networks' operational parameters simultaneously (Beuzekom et al., 2015).

Analysing and optimizing multi-energy systems mathematically will be cumbersome, if not impossible. Thanks to the computational power of computers, metaheuristic optimisation techniques are getting wider acceptance as they are more suitable to handle highly nonlinear objective functions and constraints when compared to the conventional deterministic approaches. Varieties of optimisation techniques that are used in the energy field include: Genetic Algorithm (Nemati et al., 2018; Subbaraj et al., 2009), Teaching Learning Based Algorithms (Niknam et al., 2013; Shabanpour- 
Haghighi et al., 2014), Honey Bee Mating Algorithms (Niknam et al., 2011), Mixed Integer Linear Programming (Mazairac et al., 2015; Nemati et al., 2018; Wang et al., 2018), and Particle Swarm Optimisations (Aote et al., 2016; Attous and Labbi, 2009; Ayele et al., 2019; Hazra and Sinha, 2011; Juneja and Nagar, 2016).

Two main gaps are identified that are not well addressed in the literatures discussed above:

- Exergy analysis applied on DHN mainly focussed on the power plants and/or substations. The exergy destruction due to temperature and pressure variations across the pipes of the DHN, both on the supply and return sides, are not properly dealt.

- Thermo-economic optimisation of DHNs consisting of coupling devices, such as HPs, did not take the electricity distribution losses into account. Optimal placement and sizing of heat sources is not considered either.

This paper aims at filling the above-mentioned gaps by following a step-by-step approach. An extended energy hub approach is used to formulate and solve the steady state load flow problems for both heating and electricity networks simultaneously. The details of the load flow solution, such as temperature, mass flow rate and hydraulic heads on both supply and return pipe networks of the DHN, are used to calculate exergy efficiencies of all branches and nodes in the DHN. By then, the lossy branches are isolated to get optimised DHN topology. Once the network topology is optimised, the best locations for HPs are determined using a nested Particle Swarm Optimisation (PSO) algorithm. This is followed by a thermo-economic optimisation in which temperature levels, cost of pumping energy, cost of electricity, cost of heat, capacity limits in both electricity and heating networks and sizes of HPs are duly considered.

The rest of this paper is organized as follows. The methodology is discussed in Section 2. The case study selected to demonstrate the proposed methodology is described in Section 3. Section 4 presents the results and discussions while Section 5 concludes the main findings of the paper.

\section{Methodology}

\subsection{A step-by-step approach}

A step-by-step approach, as shown in Fig. 1, enables us to explore and compare the added values of each step, instead of putting all of them into a single optimisation problem. It starts by formulating all the mathematical equations that describe the electricity and heat power flows and combining them into a single load flow problem (step 1 in Fig. 1). To make sure that the energy and mass balances governing both networks are guaranteed, the load flow problem needs always to converge into a feasible solution.

An integrated optimal power flow is run in order to determine the economical dispatch of the CHP, wind plant and HPs without violating network constraints (step 2 in Fig. 1). As DHNs are designed and installed by taking a margin for reliability and future expansions, it is not uncommon to find meshed DHN topologies with pipes running below their capacity. In that case, isolating non-critical branches could reduce distribution losses. Both of energy and exergy analyses are employed to identify the lossy branches iteratively (steps 2, 3, 4 and 5 in Fig. 1).

The operation of the DHN can be further improved by optimally placing and sizing movable heat sources, such as heat pumps (step 6 in Fig. 1). This is followed by consideration of thermo-economic optimisation in which the temperature profile of heat sources and the return temperature of substations on the primary side are considered to further reduce the operational cost of the DHN (steps 7 and 8 in Fig. 1). The details of the mathematical equations describing the system model and the optimisation algorithm are discussed in the following sections. 


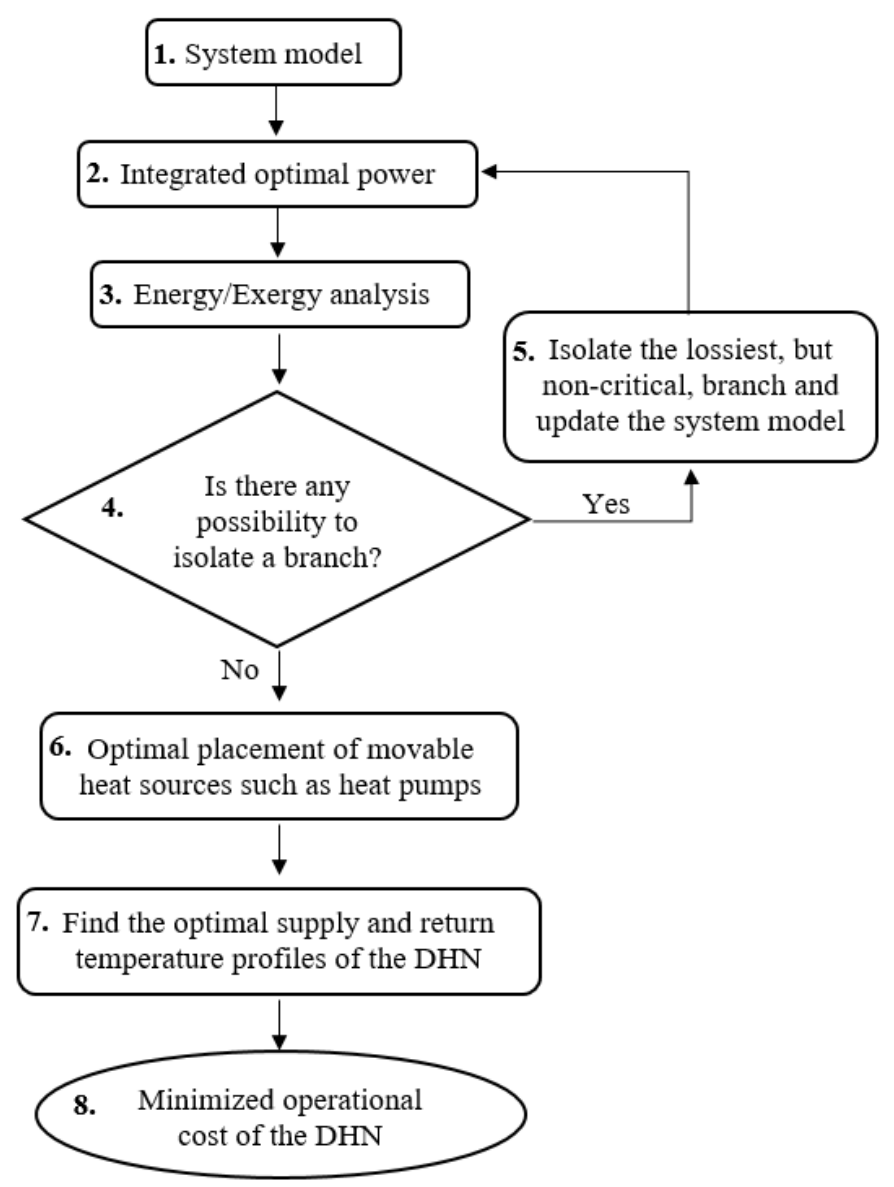

Fig. 1. A step-by-step approach for operational optimisation of a DHN.

\subsection{System model}

An extended energy hub approach, the details of which can be found in (Ayele et al., 2018a), is used in this paper to model the interaction between different energy carriers including various energy conversion technologies. Figure 2 shows the three parts of a general multi-energy system (MES): the energy hub, the point of interconnection and the energy network. Local demands, local generations and coupling devices are altogether represented by the energy hub while the point of interconnection acts as an interface between the energy hub and the remaining part of the network. Coupled electricity and heating networks are considered in this paper.

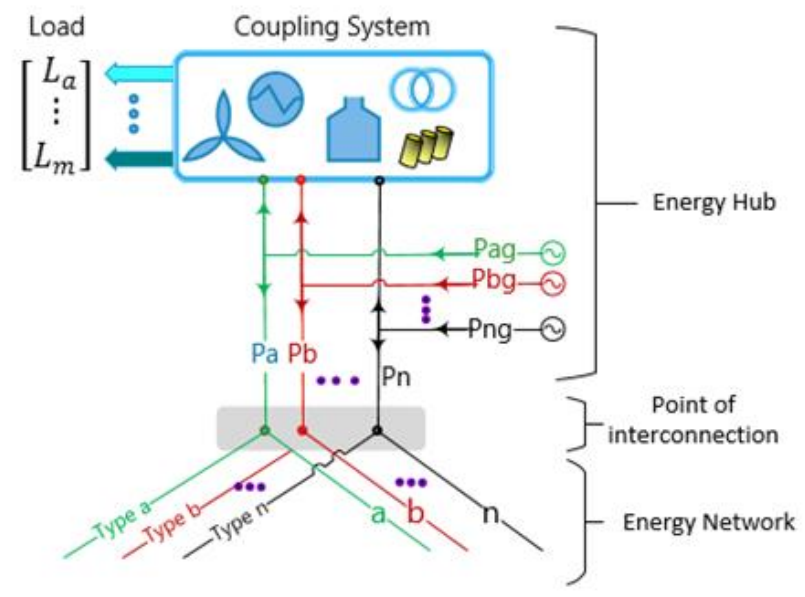

Fig. 2. An extended energy hub representation of a general MES (with permission from (Ayele et al., 2018a)). 


\subsubsection{Model for the electricity network}

For each hub $k$, the per unit active $\left(P_{e l}\right)$ and reactive $\left(Q_{e l}\right)$ power injections, which are given by (1a) and (1b), defines the electrical sub-model (Ayele et al., 2018a). These equations are used to determine the electrical network parameters such as voltage magnitude, voltage angle, active and reactive power flows and losses in the electricity network.

$P_{e l(k)}=\sum_{j=1}^{N}\left|V_{k}\right|\left|V_{j}\right|\left(G_{k j} \cos \theta_{k j}+B_{k j} \sin \theta_{k j}\right)$

$Q_{e l(k)}=\sum_{j=1}^{N}\left|V_{k}\right|\left|V_{j}\right|\left(G_{k j} \sin \theta_{k j}-B_{k j} \cos \theta_{k j}\right)$

where $\theta_{k j}$ is a voltage angle difference between bus $k$ and bus $j ; G_{i j}+j B_{i j}=Y_{i j}$ is an element of the network admittance matrix, $\left|V_{k}\right|$ denotes a voltage magnitude at bus $k$ and $N$ is the number of buses.

\subsubsection{Model for the $\mathrm{DHN}$}

The steady state thermo-hydraulic model of a district heating network is defined by (2) - (6) (Ayele et al., 2018a). These equations are used to determine the heating network parameters, such as temperature, mass flow rate, heat power flows and hydraulic heads. Equation (2) gives the heat power injection $(P h)$ into the network from hub k.

$P_{h(k)}=C_{p} \dot{m}_{k}\left(T_{s k}-T_{r k}\right)$

where $\dot{m}_{k}$ is the nodal mass flow rate flowing from hub $k$ into the supply pipe network of the DHN; $T_{s k}$ and $T_{r k}$ are the supply and return temperatures at hub $k$, respectively. $C_{p}$ is the specific heat capacity of water.

The nodal mass flow ( $\dot{m}_{k}$ ) at each hub is subject to the continuity of flow equation given by (3) which takes all pipe flows connected to the hub. The pipe flows are further related to the hydraulic heads using pressure drop equations, as defined in (4).

$\sum_{k}$ (all mass flows into the node $)=\sum_{k}$ (all mass flows out of the node $)$

$H_{j}-H_{i}=K_{i j} \dot{m}_{j i}\left|\dot{m}_{j i}\right|$

where $H_{i}$ and $H_{j}$ are hydraulic heads at nodes $i$ and $j ; \dot{m}_{j i}$ is pipe mass flow from node $j$ to node $i$ and $K_{i j}$ is the corresponding pressure resistance coefficient.

Equation (5) describes the energy balance of mixing water at a given node while (6) represent the temperature drop across a pipe.

$\sum\left(T_{j-\text { in }} \dot{m}_{j-\text { in }}\right)=T_{j-\text { out }} \sum\left(\dot{m}_{j-\text { out }}\right)$

$T_{w_{-} \text {end }}-T_{o}=\left(T_{w_{-} \text {start }}-T_{o}\right) e^{-\left(\frac{2 \pi z L U}{C_{p} \dot{m}}\right)}$

$U=\left(\frac{R_{4}}{R_{1} h_{w}}+\frac{R_{4}}{k_{2}} \ln \left|\frac{R_{2}}{R_{1}}\right|+\frac{R_{4}}{k_{3}} \ln \left|\frac{R_{3}}{R_{2}}\right|+\frac{R_{4}}{k_{4}} \ln \left|\frac{R_{4}}{R_{3}}\right|\right)^{-1}$

Terms $\left(\dot{m}_{j-i n}, T_{j-i n}\right)$ in (5) denote the incoming mass flow rates and water temperatures at a given node $j$, respectively while terms $\left(\dot{m}_{j-\text { out }}, T_{j-\text { out }}\right)$ represent the corresponding values for the outgoing mass flow rates. $T_{w_{-} e n d}$ and $T_{w_{-} s t a r t}$ are outlet and inlet water temperatures, respectively. $T_{o}$ is the soil temperature at the surface of the pipe; $\mathrm{U}$ is the overall heat transfer coefficient; $R_{1}, R_{2}, R_{3}$ and $R_{4}$ are the inner radius of carrier pipe, outer radius of the carrier pipe, outer radius of an insulation layer and outer radius of an outer jacket, respectively; $h_{w}, k_{2}, k_{3}$ and $k_{4}$ represent the convective coefficient of water, thermal conductivity of carrier pipe, thermal conductivity of the insulating material and thermal conductivity of the outer jacket. 


\subsubsection{Coupling equations}

In addition to the above equations, which govern the network part of the energy system, there are additional equations that define the conversion between different energy carriers at each hub. These equations, as shown in (7a), relates the demands, generations, injections into the network and conversion between different energy carriers at a given hub (Ayele et al., 2018a).

$$
\left[\begin{array}{c}
L_{P e l(k)} \\
L_{Q e l(k)} \\
L_{h(k)}
\end{array}\right]=\left[\begin{array}{llll}
C_{k-e p(e p)} & C_{k-e p(e q)} & C_{k-e p(h)} & C_{k-e p(f)} \\
C_{k-e q(e p)} & C_{k-e q(e q)} & C_{k-e q(h)} & C_{k-e p(f)} \\
C_{k-h(e p)} & C_{k-h(e q)} & C_{k-h(h)} & C_{k-e p(f)}
\end{array}\right]\left[\begin{array}{c}
P_{e l g(k)}-P_{e l(k)} \\
Q_{e l g(k)}-Q_{e l(k)} \\
P_{h g(k)}-P_{h(k)} \\
P_{f g(k)}
\end{array}\right]
$$

where $L_{P e l(k)}, L_{Q e l(k)}$ and $L_{\mathrm{h}(k)}$ are the active electricity, reactive electricity and heat demands at hub $k ; C_{k-\delta(\gamma)}$ represent a coupling coefficient at hub $k$ relating generation type $\gamma$ with load type $\delta$. Subscripts $e p, e q$ and $h$ indicate active electric, reactive electric and heat carriers, respectively. $P_{e l g(k)}, Q_{e l g(k)}, P_{h g(k)}$ and $P_{f g(k)}$ are active electricity, reactive electricity, heat and fuel powers locally generated at hub $\mathrm{k}$.

Specifically, the coupling equations for an energy hub consisting of a CHP and an HP, both running at unity power factor can be adapted from (Ayele et al., 2019, 2018b) as shown in (7b).

$$
\left[\begin{array}{c}
L_{e p}+P_{e p-H P} \\
L_{e q} \\
L_{h}-P_{e p-H P} * C O P
\end{array}\right]=\left[\begin{array}{cccc}
1 & 0 & 0 & \eta_{e l} \\
0 & 1 & 0 & 0 \\
0 & 0 & 1 & \eta_{t h}
\end{array}\right]\left[\begin{array}{c}
P_{e p g}-P_{e p} \\
P_{e q g}-P_{e q} \\
P_{h g}-P_{h} \\
P_{f g}
\end{array}\right]
$$

where $P_{e p-H P}$ denotes the electricity consumption of the heat pump; COP stands for coefficient of performance of the HP, $\eta_{e l}$ and $\eta_{t h}$ are the electrical and thermal efficiencies of the CHP plant. If any of the HP or CHP or both are missing in a given energy hub, equation (7b) is modified by setting the corresponding terms to zero.

\subsection{Exergy analysis}

Equations (1) - (7), mentioned above, are solved using Newton-Raphson iterative method giving the load flow solution that describes the operating conditions of both the DHN and the electricity network. The load flow solution is then used to calculate exergy flows in the DHN.

The exergy streams involved in the DHN are the water flows at different temperature and pressure. These physical exergies are computed using (8a) while exergy balance for a branch or a node are governed by equation (8b) (Bejan et al., 1996; Dincer and Rosen, 2013).

$B_{p h}=\dot{m}\left\{C_{p}\left(T-T_{o}-T_{o} \ln \frac{T}{T_{o}}\right)+\frac{P-P_{o}}{\rho}\right\}$

$E_{\text {in }}=E_{\text {out }}+E_{\text {destroyed }}$

where $B_{p h}$ is the physical exergy of a mass flow $\dot{m}$ at temperature $T$ and pressure $P$ with respect to the restricted dead state reference of temperature $T_{o}$ and pressure $P_{o} . \rho$ is density of water. $E_{\text {in }}$ is the total exergy flowing into a pipe/node while $E_{\text {out }}$ is the total exergy flowing out of a pipe/node. $E_{\text {destroyed }}$ is the amount of exergy destroyed in a pipe/node.

Circulation pumps are used to circulate the water in the DHN. Their electricity consumption is the sum of two parts: the first is due to the pressure drop across each pipe $\left(W_{e(\text { branch })}\right)$ and the second is 
due to the minimum hydraulic head gap required between the supply and return sides at each of the

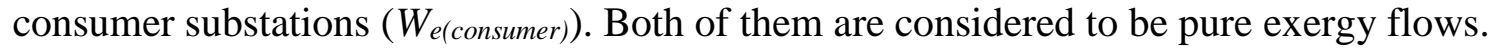

For a given branch, there will be the same mass flow on both supply and return pipes. It implies that the circulation pumps on the return and supply pipes consume the same amount of electricity. Hence, the electricity consumed by the branch, $W_{e(b r a n c h)}$ in Watt, to compensate the pressure drop on both supply and return sides can be computed using (9a) (Ayele et al., 2019).

$W_{e(\text { branch })}=\left(1+C_{l o c}\right) * 2\left(\frac{g *\left|\Delta H_{i j} * \dot{m}_{i j}\right|}{\eta}\right)_{\text {pipe }}$

where $g$ is the gravitational acceleration $\left(9.81 \mathrm{~m} / \mathrm{s}^{2}\right) ; \Delta H_{i j}$ is the frictional head loss on a straight pipe connecting nodes $i$ and $j ;\left|\dot{m}_{i j}\right|$ is magnitude of the mass flow through the pipe and $\eta$ is efficiency of the circulation pump (it is assumed to be $80 \%$ in this study). The $C_{l o c}$ is a fraction to take the local pressure losses due to valves and junctions into account while the factor 2 is due to equal pressure drop on both supply and return pipes.

On the other hand, the additional electricity required by the circulation pumps in order to guarantee sufficient hydraulic head at each of the heat consuming substations is computed using (9b) (Ayele et al., 2019).

$W_{e(\text { consumer })}=\left(\frac{g * \Delta H_{\text {con }}}{\eta}\left|\dot{m}_{\text {con }}\right|\right)_{\text {consumer }}$

where $\Delta H_{c o n}$ is the hydraulic head difference at the consumer substation in meter while $\left|\dot{m}_{\text {con }}\right|$ is the magnitude of mass flow rate on the primary side of the substation. In this study, the values of $C_{l o c}$ and $\Delta H_{c o n}$ are assumed to be 0.3 and $5.1 \mathrm{~m}(\approx 50 \mathrm{kPa})$, respectively (Wang et al., 2017).

\subsection{Particle Swarm Optimisation (PSO)}

First developed by (Kennedy and Eberhart, 1995), PSO is an optimisation algorithm which tries to find the global best value in analogy to the way a flock of birds scatter and regroup. The whole group is referred to as a swarm and its individual members are called particles. If there are $M$ variables of optimisation, then each particle in the swarm defines a point in $M$-dimensional space, usually referred to as position of the particle. In each iteration, all the particles try to adjust their position by taking their own past experience and the social knowledge into account. Randomness is also included in the algorithm to minimize the possibility of being trapped by a local optimum. The position of particle $i$ with $M$ number of optimisation variables is defined as shown in (10a).

$x_{i}=\left(x_{i 1}, x_{i 2}, \ldots, x_{i M}\right)$

The new direction and speed of the particle $\left(v_{i-n e w}\right)$ is updated using $(10 \mathrm{~b})$ which is then added to the older position to determine the new position of the particle $\left(x_{i-n e w}\right)$ as shown in $(10 \mathrm{c})$.

$$
\begin{aligned}
& v_{i-n e w}=\omega v_{i o}+c_{1} r_{1}\left(x_{i-b e s t}-x_{i}\right)+c_{2} r_{2}\left(x_{g-b e s t}-x_{i}\right) \\
& x_{i-n e w}=x_{i}+v_{i-n e w}
\end{aligned}
$$

where $\omega$ is the inertia/damping factor; $v_{i o}$ is the current velocity of particle $i ; c_{1}$ is a self-accelerating (exploration) factor; $c_{2}$ is a global accelerating (exploiting) factor; $x_{i}$ is the current position of particle $i$; $x_{i-b e s t}$ is the best position of the particle in the past; and $x_{g-b e s t}$ is the global best position achieved by the swarm in the past. $r_{1}$ and $r_{2}$ are random numbers varying between 0 and 1 . 
Ullmann et al., (2017) suggested fixed values of personal and global acceleration factors $\left(c_{1}=c_{2}=\right.$ 1.494) while (Aote et al., 2016) argued that better results can be found using a step by step variation in the following order: $c_{1}$ decreasing from 2.5 to 0.5 and $c_{2}$ increasing from 0.5 to 2.5 . The logic behind such variation is to explore locally in the first iterations and then fine-tune the global best towards the last iterations. Both approaches are tested for the problem at hand and the latter is found to give faster convergence. The value of $\omega$ is also made to vary from 0.9 to 0.4 (Aote et al., 2016). The values of maximum iteration and the number of particles to be considered highly depend on the type of problem and its number of decision variables.

The objective function of the optimisation problem considered in this paper is minimization of the operating cost of the district heating network, as given by (11).

$\min \left\{C_{P h g}+C_{P e l g}+C_{P h-\text { imported }}+C_{P e l \text {-imported }}+C_{W e}\right\}$

where $C_{P h g}, C_{P e l g}, C_{P h-i m p o r t e d}$, and $C_{P e l-i m p o r t e d}$ are costs of the generated heat, generated electricity, imported heat and imported electricity, respectively while $C_{W e}$ is the cost of electricity used by circulation pumps.

There are both equality and inequality constraints that should not be violated while achieving the objective function. All the equations (1) - (7) discussed Section 2.2 are taken as equality constraints while equations (12a) - (12e) define the main inequality constraints of the bus voltage limits, the maximum transmission line ampacity, the maximum allowed mass flow rate in each pipe, the limit on the supply temperature of heat source hubs and the allowed return temperature at heat consuming hubs, respectively. The temperature limits depend on the characteristics of heat sources, the temperature levels required at the secondary side of heat consumers and the regulations of the governing municipality, such as Legeionellosis issues (Frederiksen and Werner, 2013).

$V_{\min } \leq\left|V_{k(\text { perunit })}\right| \leq V_{\max }$

$0 \leq\left|I_{i j(r m s)}\right| \leq I_{\max }$

$0 \leq\left|\dot{m}_{i j}\right| \leq \dot{m}_{\max }$

$T_{s(\text { mini })} \leq T_{s(k)} \leq T_{s(\max )}$, for $\dot{m}_{k} \gg 0$

$T_{r(\min i)} \leq T_{r(k)} \leq T_{r(\max )}$, for $\dot{m}_{k} \ll 0$

\section{Case study}

\subsection{Base case network topology}

A hypothetical DHN that has six nodes and three loops, shown in Fig 3, is considered as a case study. The solid red lines with arrows represent the supply pipe network while the dotted lines with arrows represent the return pipe network of the DHN. The arrows indicate the positive direction of mass flows. The black solid lines without arrows represent the electric distribution network. Each hexagon represents an energy hub while the grey circles represent nodes/buses at which the corresponding hubs interact with the network. Hub1 is considered as a slack hub. An import/export of power from/to the neighbourhood is indicated by a positive/negative production of heat and electricity at this hub. 


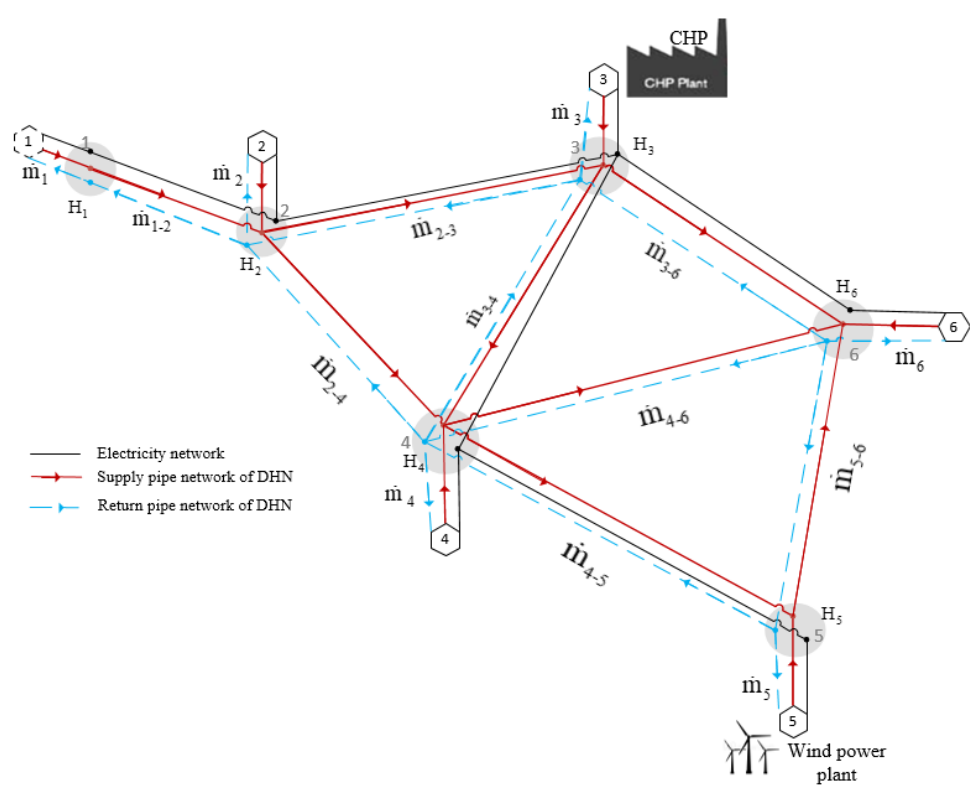

Fig. 3 A hypothetical electrified district heating network.

As it can be seen from Fig. 3, though the DHN is meshed, the electricity distribution network is kept to be radial, as the focus is on the DHN. The electrical distribution network is considered only for delivering the electricity required by the DHN. No electrical load is considered at each hub, except for the consumption of the HPs. By doing so, the electricity lost in the network, only for electrifying the DHN, can be computed and taken into account in the optimisation.

The heat demands at each hub are summarised in Table 1. To supply these demands, a gas-fired CHP and a wind power plant are assumed to be permanently connected at Hub 3 and Hub 5, respectively. In addition, two HPs are used as means of electrifying the DHN on top of the CHP. The scope of this paper is limited to the operational optimisation. Hence, the distribution network and all the technologies are assumed existing and operational.

Table 1. Heat demand at different hubs.

\begin{tabular}{lllllll}
\hline Hubs & $\mathbf{1}$ & $\mathbf{2}$ & $\mathbf{3}$ & $\mathbf{4}$ & $\mathbf{5}$ & $\mathbf{6}$ \\
\hline Heat demand $(\mathbf{k W})$ & 0 & 500 & 200 & 1000 & 200 & 500 \\
\hline
\end{tabular}

\subsection{Assumptions}

All the DHN pipes are assumed to be DN50 type with standard insulation, and their parameters are taken from (Isoplus, n.d.). In order to avoid noise and wearing in the pipes, a maximum flow speed of $3.5 \mathrm{~m} / \mathrm{s}$ is adopted (Wang et al., 2017; Zeng et al., 2016) which corresponds to a maximum flow rate of $7.85 \mathrm{~kg} / \mathrm{s}$ for a DN50 pipe. The electricity network is assumed to consist of balanced $4.16 \mathrm{kV}$ three phase ACSR Waxwing conductors with maximum allowed line current of 480 A (Glover et al., 2012). The allowed nodal voltage range is between 0.95 and 1.05 per-unit. The details of the pipe and insulation parameters together with the resistance and reactance of the electrical transmission lines are presented in Table A.1, Appendix A.

The water in the DHN pipes is incompressible with constant density $(982.6 \mathrm{~kg} / \mathrm{m} 3)$, specific heat capacity $(4.185 \mathrm{~kJ} / \mathrm{kgK})$, viscosity $(485 \mu \mathrm{NS} / \mathrm{m} 2)$ and conductivity $(0.6516 \mathrm{~W} / \mathrm{mk})$. The restricted dead state references are taken at a temperature of $268.15 \mathrm{~K}$, which is equal to the presumed soil temperature at the surface of the DHN pipe $\left(-5^{\circ} \mathrm{C}\right)$, and a pressure of $10^{5} \mathrm{~Pa}$. 
The CHP plant has $1000 \mathrm{~kW}$ of gas intake capacity with typical thermal and electrical efficiency of $47 \%$ and $38 \%$, respectively (Campos Celador et al., 2011). For the given simulation hour, the wind power plant has a maximum of $125 \mathrm{~kW}$ power output. The two HPs have $125 \mathrm{~kW}$ and $380 \mathrm{~kW}$ electrical ratings both running at a $\mathrm{COP}$ of 4.0. Their locations vary depending on the scenarios that are discussed in Section 3.3.

The price of imported electricity and heat from the neighbourhood are $0.22 € / \mathrm{kWh}$ and $0.1 € / \mathrm{kWh}$, respectively. Selling prices of $0.132 € / \mathrm{kWh}$ of electricity and zero for heat are assumed when exporting to the neighbourhood. The price of gas used by the CHP plant is $0.07 € / \mathrm{kWh}$. Operational cost of the wind power plant is negligible.

\subsection{Scenarios}

A stepwise procedure is followed to arrive at the best operational strategy of the system. For comparison purpose, the procedures are categorised into four scenarios. The electricity network topology remains the same in all the scenarios.

\subsubsection{Scenario I - Base case}

This scenario corresponds to step 2 in Fig. 1. The network topology as shown in Fig 3 is considered. The $125 \mathrm{kWe}$ and $380 \mathrm{kWe}$ HPs are placed at Hubs 5 and 3, respectively. All sources' supply temperatures are assumed at $85{ }^{\circ} \mathrm{C}$ while all the return temperatures from the consumers are set at 40 ${ }^{\circ} \mathrm{C}$. Optimal power flow is run using a single PSO (population size of 20 and a maximum iteration of 100) algorithm.

\subsubsection{Scenario II - Reduced topology}

In this scenario, a lossiest branch is identified and isolated one at a time. The process is repeated until all non-critical branches are isolated (steps 2, 3, 4 and 5 in Fig. 1.). A maximum of three branches can be isolated from the three loops shown in Fig 3. The HPs are kept at the same hubs as they were in the base case scenario and the optimal power flow is run under the same conditions. First, the operating parameters of the DHN (mass flow, pressure head and temperature) that are found from the optimal power flow of the base case scenario are used to compute both energy and exergy losses across each branch. Accordingly, the $1^{\text {st }}$ lossiest branch is identified and isolated. The optimal power flow is then run again to identify and isolate the second lossiest branch. The procedure is repeated to identify the third lossiest branch, at the end giving a reduced topology of the DHN. Lastly the optimal power flow is computed on the reduced topology. The reduced network topology is further used in the consecutive scenarios.

\subsubsection{Scenario III - Optimal placement of HPS}

This scenario corresponds to step 6 in Fig. 1. A nested PSO algorithm is used to find out the optimal placement of the two HPs. In a nested PSO algorithm, the details of which is available in (Ayele et al., 2019), the outer PSO is dedicated to find the best location of the HPs while the inner PSO solves the optimal power flow based on the location of HPs dictated by the outer PSO loop. The outer loop of the PSO has a population size of 5 and maximum iteration of 10 while the internal PSO has a population size of 20 and a maximum iteration of 100. A reduced network topology is used in this scenario while keeping the same other conditions as the previous scenarios.

\subsubsection{Scenario IV - Thermo-economic optimisation}

This scenario deals with the thermo-economic optimisation of the reduced network topology after the optimal location of the HPs are determined in Scenario III (steps 7 and 8 in Fig. 1). The supply temperature range is taken between $60{ }^{\circ} \mathrm{C}$ and $95{ }^{\circ} \mathrm{C}$ while a return temperature range is assumed between $30{ }^{\circ} \mathrm{C}$ and $55^{\circ} \mathrm{C}$. A single PSO (population size of 30 and a maximum iteration of 100) is applied to determine not only the economic dispatch but also the optimal temperature profiles at the sources and consumer hubs. 


\section{Results and discussions}

\subsection{Base case (Scenarios I)}

\subsubsection{Energy analysis}

The hub-level load flow results of Scenario I are presented in Table 2. The table shows the local electricity generation (Pepg); the consumption of HPs (HP Lep); the heat generated by the HPs (Hp $P h g$ ); the electricity and heat produced by the CHP (CHP Pepg and CHP Phg); the heat generated locally $(P h g)$; the heat demand $(L h)$; and the nodal mass flow rate $(\dot{m})$. It also shows the nodal temperatures ( $T s$ and $T r$ ) and hydraulic heads $(H s$ and $H r$ ) on the supply and return sides of the DHN.

The total amount of heat demand is $2400 \mathrm{~kW}$. The CHP generated about $470 \mathrm{~kW}$ of heat while the two HPs produced $2020 \mathrm{~kW}$ of heat, which add up to $2490 \mathrm{~kW}$. Although the total heat produced is $90 \mathrm{~kW}$ more than the total heat demand, it is not enough to compensate the losses in the network. Hence, additional $46.19 \mathrm{~kW}$ of heat is imported from the neighbourhood. On the other hand, the wind and the CHP plants produced $125 \mathrm{~kW}$ and $380 \mathrm{~kW}$ of electricity, respectively. The electricity lost in the distribution network is zero because all the electricity is consumed locally by the HPs.

Table 2: Nodal results of the optimal power flow (base case).

\begin{tabular}{|c|c|c|c|c|c|c|c|c|c|c|c|c|}
\hline Hub & $\begin{array}{l}\text { Pepg } \\
(\mathbf{k W})\end{array}$ & $\begin{array}{c}\text { HP Lep } \\
(\mathbf{k W})\end{array}$ & $\begin{array}{c}\text { HP Phg } \\
(\mathbf{k W})\end{array}$ & $\begin{array}{c}\text { CHP Pepg } \\
(\mathbf{k W})\end{array}$ & $\begin{array}{c}\text { CHP Phg } \\
(\mathbf{k W})\end{array}$ & $\begin{array}{l}\text { Phg } \\
(\mathbf{k W})\end{array}$ & $\begin{array}{c}\text { Lh } \\
(\mathbf{k W})\end{array}$ & $\underset{(\mathrm{kg} / \mathrm{s})}{\dot{m}}$ & Ts $\left({ }^{\circ} \mathbf{C}\right)$ & $\operatorname{Tr}\left({ }^{\circ} \mathrm{C}\right)$ & $\begin{array}{l}\text { Hs } \\
(\mathbf{m})\end{array}$ & $\operatorname{Hr}(\mathbf{m})$ \\
\hline 1 & 0.00 & 0.00 & 0.00 & 0.00 & 0.00 & 46.19 & 0.0 & 2.98 & 43.40 & 39.69 & 30.00 & 30.00 \\
\hline 2 & 0.00 & 0.00 & 0.00 & 0.00 & 0.00 & 0.00 & 500.0 & -5.01 & 63.84 & 40.00 & 28.23 & 31.77 \\
\hline 3 & 0.00 & 380.0 & 1520.0 & 380.0 & 470.0 & 0.00 & 200.0 & 9.35 & 85.00 & 39.26 & 50.27 & 9.73 \\
\hline 4 & 0.00 & 0.00 & 0.00 & 0.00 & 0.00 & 0.00 & 1000.0 & -6.08 & 79.32 & 40.00 & 25.51 & 34.49 \\
\hline 5 & 125.0 & 125.0 & 500.00 & 0.00 & 0.00 & 0.00 & 200.0 & 1.52 & 85.00 & 37.81 & 28.24 & 31.76 \\
\hline 6 & 0.00 & 0.00 & 0.00 & 0.00 & 0.00 & 0.00 & 500.0 & -2.76 & 83.26 & 40.00 & 27.46 & 32.54 \\
\hline
\end{tabular}

Table 3, on the other hand shows the branch level load flow results. The table shows the pipe mass flow rate, the inlet and outlet hydraulic heads and temperatures both on the supply and return pipes. It can be seen that the highest temperature drops both on the supply and return pipes occurred on the branch connecting Hubs 5 and 6. This is associated to the lowest mass flow in the branch resulting in a higher residence time and, as a result, causing higher temperature drop. The table also shows the net heat delivered, the losses and energy efficiency of each branch. It also shows the corresponding pumping energy consumption. The total heat loss in this network (as can be computed from Tables 2 or 3 ) is about $136.19 \mathrm{~kW}$ giving a DHN energy efficiency of $94.33 \%$.

Table 3: Branch results of the optimal power flow (base case).

\begin{tabular}{|c|c|c|c|c|c|c|c|c|c|c|c|c|c|c|}
\hline \multicolumn{2}{|c|}{ Hubs } & \multirow{2}{*}{$\begin{array}{c}\text { Flow } \\
(\mathbf{k g} / \mathbf{s})\end{array}$} & \multicolumn{4}{|c|}{ Supply Pipe Network of DHN } & \multicolumn{4}{|c|}{ Return Pipe Network of DHN } & \multicolumn{4}{|c|}{ Branch i to $\mathbf{j}$} \\
\hline $\mathbf{i}$ & $\mathrm{j}$ & & $\mathrm{H}_{\mathrm{i}}(\mathrm{m})$ & $\mathrm{H}_{\mathrm{j}}(\mathrm{m})$ & Tsi $\left({ }^{\circ} \mathrm{C}\right)$ & $\mathrm{Tsj}\left({ }^{\circ} \mathrm{C}\right)$ & $\mathrm{H}_{\mathrm{i}}(\mathrm{m})$ & $\mathrm{H}_{\mathrm{j}}(\mathrm{m})$ & $\operatorname{Tri}\left({ }^{\circ} \mathrm{C}\right)$ & $\operatorname{Trj}\left({ }^{\circ} \mathrm{C}\right)$ & $\begin{array}{l}\text { We(branc) } \\
(\mathrm{kW})\end{array}$ & $\begin{array}{l}\text { Net heat } \\
\text { flow }(\mathrm{kW})\end{array}$ & $\begin{array}{l}\text { Loss } \\
(\mathrm{kW})\end{array}$ & $\begin{array}{c}\text { Energy } \\
\text { efficiency }\end{array}$ \\
\hline 1 & 2 & 2.98 & 30.00 & 28.23 & 43.40 & 43.35 & 30.00 & 31.77 & 39.69 & 39.74 & 0.169 & 45.04 & 1.16 & $97.14 \%$ \\
\hline 2 & 3 & -3.04 & 28.23 & 50.27 & 83.95 & 85.00 & 31.77 & 9.73 & 39.74 & 39.22 & 2.134 & 561.74 & 19.95 & $96.22 \%$ \\
\hline 2 & 4 & 1.00 & 28.23 & 25.51 & 63.84 & 61.44 & 31.77 & 34.49 & 38.43 & 40.00 & 0.087 & 90.13 & 16.65 & $84.34 \%$ \\
\hline 3 & 4 & 3.23 & 50.27 & 25.51 & 85.00 & 84.01 & 9.73 & 34.49 & 39.51 & 40.00 & 2.547 & 594.06 & 20.00 & $96.34 \%$ \\
\hline 3 & 6 & 3.09 & 50.27 & 27.46 & 85.00 & 83.97 & 9.73 & 32.54 & 39.05 & 39.56 & 2.248 & 574.32 & 19.93 & $96.28 \%$ \\
\hline 4 & 5 & -1.01 & 25.51 & 28.24 & 81.88 & 85.00 & 34.49 & 31.76 & 40.00 & 38.44 & 0.088 & 176.66 & 19.75 & $89.90 \%$ \\
\hline 4 & 6 & -0.84 & 25.51 & 27.46 & 79.60 & 83.26 & 34.49 & 32.54 & 40.00 & 38.13 & 0.052 & 139.14 & 19.42 & $87.72 \%$ \\
\hline 5 & 6 & 0.51 & 28.24 & 27.46 & 85.00 & 78.95 & 31.76 & 32.54 & 36.57 & 39.56 & 0.013 & 84.24 & 19.35 & $81.31 \%$ \\
\hline
\end{tabular}

\subsubsection{Exergy analysis}

The values of heating network parameters shown in Table 2 and Table 3 are used to compute the exergy flows in both supply and return pipes of the DHN. These values are in turn used to determine the exergy loss across each branch and at each node. 
Each node represented by the grey circle in Fig 3 has two physically separated thermal nodes: one on the supply side and the other on the return side of the DHN. Any heat flow from/to external environment is also treated as two separate flows, i.e. one on the supply side and the other on the return side with opposite direction of flow. A complete mixing of water is assumed at all nodes. The exergy destruction at each node, due to the irreversibility of mixing of water at different temperature, is calculated by taking all the input and output exergy flows both on the supply and return nodes.

The nodal exergy efficiencies, considering both supply and return nodes, are shown in Table 4 . The external input refers to the positive/negative exergy flow from/to the hub to/from the corresponding node. The total input, on the other hand, is the sum of all positive exergy flows into the node while the total output refers to the sum of positive exergy flows leaving the node. Additional exergy input due to the pumping energy requirement at the substation connecting the supply and return side nodes is indicated by We(consumer). The nodal exergy destruction is not significant as it is indicated by efficiencies that are close to $100 \%$ in Table 4 . Because of the lower temperature level, the exergy destructions on the return side nodes are relatively lower than the corresponding values of the supply side nodes. Node 2 has the lowest nodal exergy efficiency $(95.66 \%)$ due to the mixing of flows at different temperatures on the supply side. On the other hand, nodes 1 and 3 are at 100\% efficiency because of having a single mass flow passing through the node.

Table 4: Exergy flow to/from the environment and exergy efficiency at each node (base case).

\begin{tabular}{|c|c|c|c|c|c|c|c|c|}
\hline \multicolumn{4}{|c|}{ Exergy on supply side nodes (kW) } & \multicolumn{3}{|c|}{ Exergy on return side nodes ( $(\mathrm{kW})$} & \multirow{2}{*}{$\begin{array}{c}\text { We(consumer) } \\
(\mathbf{k W})\end{array}$} & \multirow{2}{*}{$\begin{array}{c}\text { Nodal exergy } \\
\text { efficiency }\end{array}$} \\
\hline Node & External input & Total input & Total output & External input & Total input & Total output & & \\
\hline 1 & 49.29 & 49.29 & 49.29 & -42.45 & 42.45 & 42.45 & 0.000 & $100.00 \%$ \\
\hline 2 & -159.64 & 203.87 & 191.63 & 72.41 & 85.99 & 85.96 & 0.314 & $95.66 \%$ \\
\hline 3 & 488.91 & 488.91 & 488.91 & -128.93 & 128.94 & 128.93 & 0.000 & $100.00 \%$ \\
\hline 4 & -280.80 & 282.64 & 280.80 & 87.94 & 87.94 & 87.94 & 0.380 & $99.40 \%$ \\
\hline 5 & 79.09 & 79.09 & 79.09 & -19.98 & 19.99 & 19.98 & 0.000 & $99.99 \%$ \\
\hline 6 & -138.75 & 180.98 & 180.93 & 39.91 & 51.12 & 51.11 & 0.173 & $99.90 \%$ \\
\hline
\end{tabular}

Table 5 shows the exergy flows in each pipe, the losses and the exergy efficiency of each branch. The exergy loss calculation for each pipe considers the exergy destruction due to heat loss and pressure drop. The exergy loss associated with the pressure drop across each pipe is equivalent to the exergy input by the corresponding circulation pump (i.e. We/2, see equation (9a)). The effect of friction on increasing the water temperature is neglected in this study. As it can be seen from the table, though the exergy losses in the return pipes are lower than the corresponding supply pipes, they are comparable and cannot be neglected.

The total exergy input into the DHN can be calculated by adding all the positive external flows on both supply and return sides of all nodes and the exergy inputs of the circulation pumps. This gives a total input of $825.76 \mathrm{~kW}$ of exergy. Out of this, $40.14 \mathrm{~kW}$ is destroyed in the branches and $15.05 \mathrm{~kW}$ is destroyed in the nodes giving an exergy efficiency of $93.32 \%$.

Table 5: Exergy of water at the inlet and outlet of branch pipes and associated losses (base case).

\begin{tabular}{|r|r|r|r|r|r|r|r|r|r|r|r|r|}
\hline \multicolumn{2}{|c|}{ Nodes } & \multicolumn{2}{|c|}{ Exergy of water in the supply pipe (kW) } & \multicolumn{2}{|c|}{ Exergy of water in the return pipe (kW) } & \multicolumn{2}{|c|}{ Branch i to j } \\
\hline $\mathbf{i}$ & $\mathrm{j}$ & $\begin{array}{c}\text { At } \\
\text { node i }\end{array}$ & $\begin{array}{c}\text { At } \\
\text { node j }\end{array}$ & \multicolumn{1}{|c|}{ Loss } & $\begin{array}{c}\text { Exergy } \\
\text { efficiency }\end{array}$ & $\begin{array}{c}\text { At } \\
\text { node i }\end{array}$ & $\begin{array}{c}\text { At } \\
\text { node j }\end{array}$ & Loss & $\begin{array}{c}\text { Exergy } \\
\text { efficiency }\end{array}$ & $\begin{array}{c}\text { Net exergy } \\
\text { flow (kW) }\end{array}$ & $\begin{array}{c}\text { Exergy } \\
\text { lost }(\mathrm{kW})\end{array}$ & $\begin{array}{c}\text { Exergy } \\
\text { efficiency }\end{array}$ \\
\hline $\mathbf{1}$ & 2 & 49.29 & 49.14 & 0.23 & $99.54 \%$ & 42.45 & 42.58 & 0.22 & $99.50 \%$ & 91.59 & 0.44 & $99.52 \%$ \\
\hline $\mathbf{2}$ & 3 & 154.73 & 158.72 & 5.06 & $96.83 \%$ & 43.37 & 41.77 & 2.67 & $94.00 \%$ & 196.51 & 7.72 & $96.22 \%$ \\
\hline $\mathbf{2}$ & 4 & 31.98 & 29.93 & 2.10 & $93.45 \%$ & 13.58 & 14.53 & 1.00 & $93.12 \%$ & 43.50 & 3.10 & $93.34 \%$ \\
\hline $\mathbf{3}$ & 4 & 168.62 & 164.50 & 5.39 & $96.82 \%$ & 44.93 & 46.67 & 3.01 & $93.72 \%$ & 209.43 & 8.40 & $96.14 \%$ \\
\hline $\mathbf{3}$ & 6 & 161.58 & 157.55 & 5.15 & $96.83 \%$ & 42.23 & 43.86 & 2.75 & $93.88 \%$ & 199.78 & 7.90 & $96.19 \%$ \\
\hline $\mathbf{4}$ & 5 & 49.19 & 52.48 & 3.34 & $93.65 \%$ & 14.59 & 13.63 & 1.00 & $93.14 \%$ & 62.81 & 4.34 & $93.54 \%$ \\
\hline $\mathbf{4}$ & 6 & 39.03 & 42.18 & 3.18 & $92.47 \%$ & 12.15 & 11.21 & 0.97 & $92.05 \%$ & 50.24 & 4.15 & $92.37 \%$ \\
\hline $\mathbf{5}$ & 6 & 26.61 & 23.44 & 3.18 & $88.05 \%$ & 6.36 & 7.25 & 0.90 & $87.64 \%$ & 29.80 & 4.08 & $87.97 \%$ \\
\hline
\end{tabular}




\subsection{Reduced topology (Scenario II)}

Energy and exergy efficiencies of branches are used to isolate the three lossiest branches step by step.

\subsubsection{Energy analysis}

Referring the results of Table 3, the branch connecting Hubs 5 and 6 is the lossiest branch $(81.31 \%$ efficiency). The next lossiest branches are those between Hubs 2 and 4, and Hubs 4 and 6, respectively. However, the $2^{\text {nd }}$ and the $3^{\text {rd }}$ lossiest branches may be different as the optimal power flow could result in a different solution once the $1^{\text {st }}$ lossiest branch is isolated. Having this in mind, the branch between Hubs 5 and 6 is first isolated and the optimal power flow is repeated with the new topology. The results are tabulated in Appendix B, Table B.1 and Table B.2. As it can be seen from Table B.2, the next lossiest branch is the one between Hubs 4 and 6, and not the one between Hubs 2 and 4 (contradicting with the one indicated in Table 3). This confirms the importance of a step-bystep approach. The optimal power flow is repeated again after removing the branch 4-6. The results are presented in Tables B.3 and B.4. In particular, Table B.4 shows that the third lossiest branch is the one between Hubs 1 and 2. However, this branch is mandatory to keep all hubs connected and cannot be isolated. Therefore, we take the next lossiest branch, which is branch 2-4. The remaining branches are critical to keep all nodes connected to the DHN.

\subsubsection{Exergy analysis}

Like the energy analysis, the branch exergy efficiencies of the base case scenario (shown in Table 5) are used to identify the $1^{\text {st }}$ lossiest branch. Accordingly, branch 5-6 has the lowest exergy efficiency $(87.97 \%)$ which is in agreement with the energy analysis. The exergy flows in the branches after isolating the branch 5-6 are summarised in Table B.5, Appendix B. The results show that the next lossiest branch is the one between Hubs 4 and 6. The resulting exergy flows after isolating the branch 4-6 are summarised in Table B.6. Accordingly, the $3^{\text {rd }}$ lossiest branch is the one between Hubs 2 and 4. Though the three branches that are isolated at the end are the same in both energy and exergy analyses, identifying the lossiest branches using exergy analysis is found to be straightforward.

\subsubsection{Reduced network topology}

Once all the branches 5-6, 4-6 and 2-4 are isolated from the base case topology (Fig 3), the reduced (optimised) topology of the DHN looks like as shown in Fig 4. This configuration is found to be optimal for the given load and generation conditions.

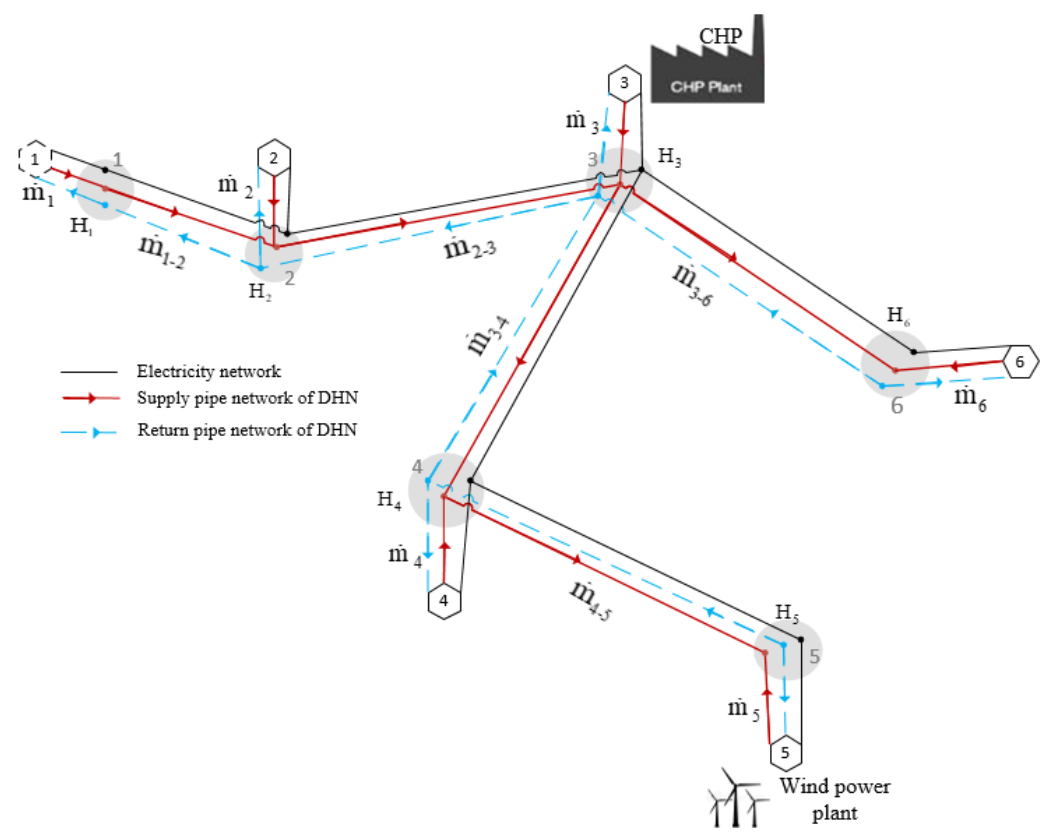

Fig. 4 The reduced network topology after isolating the lossy branches. 
An optimal power flow is then run to see how much saving is made in terms of both energy and money. The nodal and branch level results are summarised in Table 6 and Table 7 . As it can be seen from Table 6, the imported heat is zero and there is an excess of electricity exported to the neighbourhood at Hub 1. It also shows that running the CHP at full rate is found to be economical than running the heat pumps at full rate. From the two HPs, the one installed at Hub 5 is running at its full capacity $(125 \mathrm{~kW})$ because of the cheap local generation of $125 \mathrm{~kW}$ electricity from the wind plant. It also avoids the electricity loss that could exist while exporting the excess production from Hub 5 to Hub 1.

Table 6: Nodal results of the optimal power flow (reduced topology).

\begin{tabular}{|c|c|c|c|c|c|c|c|c|c|c|c|c|}
\hline Hub & $\begin{array}{l}\text { Pepg } \\
(\mathrm{kW})\end{array}$ & $\begin{array}{c}\text { HP Lep } \\
(\mathbf{k W})\end{array}$ & $\begin{array}{c}\text { HP Phg } \\
(\mathbf{k W})\end{array}$ & $\begin{array}{c}\text { CHP Pepg } \\
(\mathbf{k W})\end{array}$ & $\begin{array}{c}\text { CHP Phg } \\
(\mathbf{k W})\end{array}$ & $\begin{array}{l}\text { Phg } \\
(\mathbf{k W})\end{array}$ & Lh $(k W)$ & $\dot{m}(\mathbf{k g} / \mathbf{s})$ & Ts $\left({ }^{\circ} \mathrm{C}\right)$ & $\operatorname{Tr}\left({ }^{\circ} \mathrm{C}\right)$ & Hs (m) & Hr (m) \\
\hline 1 & -2.54 & 0.00 & 0.00 & 0.00 & 0.0 & 0.0 & 0.0 & 0.00 & 10.15 & 10.15 & 30.00 & 30.00 \\
\hline 2 & 0.00 & 0.00 & 0.00 & 0.00 & 0.0 & 0.0 & 500.0 & -2.73 & 83.83 & 40.00 & 30.00 & 30.00 \\
\hline 3 & 0.00 & 377.46 & 1509.84 & 380.00 & 470.0 & 0.0 & 200.0 & 9.34 & 85.00 & 39.49 & 47.92 & 12.08 \\
\hline 4 & 0.00 & 0.00 & 0.00 & 0.00 & 0.0 & 0.0 & 1000.0 & -5.45 & 83.83 & 40.00 & 12.30 & 47.70 \\
\hline 5 & 125.0 & 125.00 & 500.00 & 0.00 & 0.0 & 0.0 & 200.0 & 1.56 & 85.00 & 38.98 & 18.49 & 41.51 \\
\hline 6 & 0.0 & 0.00 & 0.00 & 0.00 & 0.0 & 0.0 & 500.0 & -2.73 & 83.83 & 40.00 & 30.00 & 30.00 \\
\hline
\end{tabular}

Table 7 summarises the branch power flows and associated efficiencies. The total heat loss is reduced from $136.19 \mathrm{~kW}$ (Scenario I) to $79.86 \mathrm{~kW}$ which shows a $41.37 \%$ reduction. Though the cost of pumping energy increased slightly from $1.805 € / \mathrm{h}$ to $1.88 € / \mathrm{h}$, the total operating cost has decreased from $76.42 € / \mathrm{h}$ to $71.32 € / \mathrm{h}$. The loss in the electricity distribution network is again negligible compared to the demands of the HPs.

Table 7: Branch results of the optimal power flow (reduced topology).

\begin{tabular}{|r|c|c|r|r|r|}
\hline \multicolumn{2}{|c|}{ Hubs } & \multicolumn{4}{|c|}{ Branch i to j } \\
\hline $\mathbf{i}$ & $\mathrm{j}$ & $\begin{array}{c}\text { We(branc) } \\
(\mathrm{kW})\end{array}$ & $\begin{array}{c}\text { Net heat } \\
\text { flow }(\mathrm{kW})\end{array}$ & $\begin{array}{c}\text { Loss } \\
(\mathrm{kW})\end{array}$ & $\begin{array}{l}\text { Energy } \\
\text { efficiency }\end{array}$ \\
\hline $\mathbf{1}$ & 2 & 0.000 & 0.00 & --- & --- \\
\hline $\mathbf{2}$ & 3 & 1.558 & -500.00 & 19.98 & $96.16 \%$ \\
\hline $\mathbf{3}$ & 4 & 4.422 & 719.88 & 20.02 & $97.29 \%$ \\
\hline $\mathbf{3}$ & 6 & 1.558 & 500.00 & 19.98 & $96.16 \%$ \\
\hline $\mathbf{4}$ & 5 & 0.307 & -280.12 & 19.88 & $93.37 \%$ \\
\hline
\end{tabular}

\subsection{Optimal placement of HPs (Scenarios III)}

To further reduce the distribution loss, the optimal placement of HPs is determined using the nested PSO algorithm presented in (Ayele et al., 2019). It is found that Hub 4 and Hub 6 are the best places to install the $380 \mathrm{kWe}$ and the $125 \mathrm{kWe}$ HPs, respectively. The sizing of the HPs and operating parameters of the distribution network are summarised in Table 8 and Table 9. The total heat loss is now $64.11 \mathrm{~kW}$ which shows $52.93 \%$ and $19.72 \%$ reductions from Scenarios I and II, respectively. In comparison to Scenario II (Table 6), the amount of electricity exported has increased by $3.09 \mathrm{~kW}$. As the HPs are placed relatively farther from the electricity sources, there is a higher (about $0.85 \mathrm{~kW}$ ) electricity distribution loss. On the other hand, the heat pumps are relatively closer to the heat demands when compared to Scenario II. As a result, the pumping cost has decreased from $1.88 € / \mathrm{h}$ (Scenario II) to $0.5 € / \mathrm{h}$. The total operating cost becomes $69.56 € / \mathrm{h}$ which shows $8.98 \%$ saving over Scenario I.

Table 8: Nodal results after the optimal placement and sizing of the HPs.

\begin{tabular}{|c|c|c|c|c|c|c|c|c|c|c|c|c|}
\hline Hub & $\begin{array}{l}\text { Pepg } \\
(\mathbf{k W})\end{array}$ & $\underset{(\mathbf{k W})}{\text { HP Lep }}$ & $\begin{array}{c}\text { HP Pepgt } \\
(\mathbf{k W})\end{array}$ & $\begin{array}{c}\text { CHP Pepg } \\
(\mathbf{k W})\end{array}$ & $\begin{array}{c}\text { CHP Phg } \\
(\text { (kW) }\end{array}$ & $\begin{array}{l}\text { Phg } \\
(\mathbf{k W})\end{array}$ & $\begin{array}{c}\text { Lh } \\
(\mathbf{k W})\end{array}$ & $\underset{(\mathrm{kg} / \mathrm{s})}{\dot{m}}$ & $\begin{array}{c}\text { Ts } \\
\left({ }^{\circ} \mathbf{C}\right)\end{array}$ & $\operatorname{Tr}\left({ }^{\circ} \mathrm{C}\right)$ & Hs (m) & $\operatorname{Hr}(\mathbf{m})$ \\
\hline 1 & -5.63 & 0.00 & 0.00 & 0.00 & 0.00 & 0.00 & 0.00 & 0.00 & 40.00 & 40.00 & 30.00 & 30.00 \\
\hline 2 & 0.00 & 0.00 & 0.00 & 0.00 & 0.00 & 0.00 & 500.00 & -2.79 & 82.75 & 40.00 & 30.00 & 30.00 \\
\hline 3 & 0.00 & 0.00 & 0.00 & 380.00 & 470.00 & 0.00 & 200.00 & 1.41 & 85.00 & 39.23 & 48.80 & 11.20 \\
\hline 4 & 0.00 & 373.52 & 1494.09 & 0.00 & 0.00 & 0.00 & 1000.0 & 2.53 & 85.00 & 38.34 & 53.85 & 6.15 \\
\hline 5 & 125.00 & 0.00 & 0.00 & 0.00 & 0.00 & 0.00 & 200.00 & -1.13 & 82.22 & 40.00 & 50.45 & 9.55 \\
\hline 6 & 0.00 & 125.00 & 500.00 & 0.00 & 0.00 & 0.00 & 500.00 & -0.01 & 1.00 & 1.00 & 48.80 & 11.20 \\
\hline
\end{tabular}


Table 9: Branch results after optimal placement and sizing of the HPs.

\begin{tabular}{|r|r|r|r|r|r|}
\hline \multicolumn{2}{|c|}{ Hubs } & \multicolumn{4}{|c|}{ Branch i to j } \\
\hline $\mathbf{i}$ & $\mathrm{j}$ & $\begin{array}{c}\text { We(branch) } \\
(\mathrm{kW})\end{array}$ & $\begin{array}{c}\text { Net heat } \\
\text { flow }(\mathrm{kW})\end{array}$ & $\begin{array}{c}\text { Loss } \\
(\mathrm{kW})\end{array}$ & Energy efficiency \\
\hline 1 & 2 & 0.000 & 0.00 & --- & --- \\
\hline 2 & 3 & 1.676 & -500.00 & 19.81 & $96.19 \%$ \\
\hline 3 & 4 & 0.225 & -254.57 & 19.74 & $92.80 \%$ \\
\hline 3 & 6 & 0.000 & 0.00 & --- & --- \\
\hline 4 & 5 & 0.123 & 200.00 & 19.79 & $91.00 \%$ \\
\hline
\end{tabular}

\subsection{Thermo-economic optimisation (Scenario IV)}

Unlike to the fixed supply and return temperatures applied in the previous scenarios, a thermoeconomic optimisation is done in this scenario by relaxing the supply temperature range between 60 ${ }^{\circ} \mathrm{C}$ and $95{ }^{\circ} \mathrm{C}$ and the return temperature between $30{ }^{\circ} \mathrm{C}$ and $55^{\circ} \mathrm{C}$. The nodal and branch optimisation results are presented in Table 10 and Table 11.

Hubs 3 and 4 are sources of heat as they are indicated by positive nodal mass flows in Table 10 while Hubs 2 and 5 are consumers. The return temperatures of both Hubs 2 and 5 are at $30{ }^{\circ} \mathrm{C}$ which is the lower limit. It implies that the lower the return temperature from the consumers the more economical the DHN will be.

The supply temperatures of Hubs 3 and 4 are at $95{ }^{\circ} \mathrm{C}$ and $67.76{ }^{\circ} \mathrm{C}$, respectively. Should the cost of pumping energy be not significant, both supply temperatures were expected to be equal to the minimum limit of $60{ }^{\circ} \mathrm{C}$. However, they are higher than the lower limit and Hub 3 is rather at the maximum limit. This shows that decreasing the sources temperatures further leads to not only a decrease in distribution loss, but also to an increase in a mass flow rate, which in turn requires a higher pumping energy. The optimisation found that the cost of the additional pumping energy is more expensive than the cost of heat loss that could be saved by further decreasing the supply temperatures.

Table 10: Nodal results of the thermo-economic optimisation.

\begin{tabular}{|c|c|c|c|c|c|c|c|c|c|c|c|c|}
\hline Hub & $\begin{array}{l}\text { Pepg } \\
(\mathbf{k W})\end{array}$ & $\begin{array}{c}\text { HP Lep } \\
(\mathbf{k W})\end{array}$ & $\begin{array}{c}\text { HP Pepg } \\
(\mathbf{k W})\end{array}$ & $\begin{array}{c}\text { CHP Pepg } \\
(\mathbf{k W})\end{array}$ & $\begin{array}{c}\text { CHP Phg } \\
(\mathbf{k W})\end{array}$ & $\begin{array}{l}\text { Phg } \\
(\mathbf{k W})\end{array}$ & Lh $(\mathbf{k W})$ & $\underset{(\mathbf{k g} / \mathbf{s})}{\dot{m}}$ & Ts $\left({ }^{\circ} \mathrm{C}\right)$ & $\begin{array}{c}\mathbf{T r} \\
\left({ }^{\circ} \mathbf{C}\right)\end{array}$ & Hs (m) & $\operatorname{Hr}(\mathbf{m})$ \\
\hline 1 & -7.74 & 0.00 & 0.00 & 0.00 & 0.00 & 0.00 & 0.00 & 0.00 & 10.00 & 10.00 & 30.00 & 30.00 \\
\hline 2 & 0.00 & 0.00 & 0.00 & 0.00 & 0.00 & 0.00 & 500.00 & -2.61 & 75.85 & 30.00 & 30.00 & 30.00 \\
\hline 3 & 0.00 & 0.00 & 0.00 & 380.00 & 470.00 & 0.00 & 200.00 & 0.98 & 95.00 & 29.28 & 46.44 & 13.56 \\
\hline 4 & 0.00 & 371.42 & 1485.67 & 0.00 & 0.00 & 0.00 & 1000.00 & 2.98 & 67.76 & 28.78 & 53.29 & 6.71 \\
\hline 5 & 125.00 & 0.00 & 0.00 & 0.00 & 0.00 & 0.00 & 200.00 & -1.33 & 65.84 & 30.00 & 48.67 & 11.33 \\
\hline 6 & 0.00 & 125.00 & 500.00 & 0.00 & 0.00 & 0.00 & 500.00 & 0.00 & 10.00 & 10.00 & 46.44 & 13.56 \\
\hline
\end{tabular}

Table 11: Branch results of the thermo-economic optimisation.

\begin{tabular}{|r|r|r|r|r|r|}
\hline \multicolumn{2}{|c|}{ Hubs } & \multicolumn{4}{|c|}{ Branch i to j } \\
\hline $\mathbf{i}$ & $\mathrm{j}$ & $\begin{array}{c}\text { We(branch) } \\
(\mathrm{kW})\end{array}$ & $\begin{array}{c}\text { Net heat } \\
\text { flow }(\mathrm{kW})\end{array}$ & $\begin{array}{c}\text { Loss } \\
(\mathrm{kW})\end{array}$ & Energy efficiency \\
\hline 1 & 2 & 0.000 & 0.00 & 0.00 & --- \\
\hline 2 & 3 & 1.365 & -499.99 & 17.30 & $96.66 \%$ \\
\hline 3 & 4 & 0.359 & -254.07 & 15.77 & $94.16 \%$ \\
\hline 3 & 6 & 0.000 & 0.00 & 0.00 & --- \\
\hline 4 & 5 & 0.196 & 200.00 & 15.83 & $92.66 \%$ \\
\hline
\end{tabular}

The total distribution heat loss in Scenario IV is decreased to $55.67 \mathrm{~kW}$, as it can be calculated from Table 10 or Table 11. This shows a $13.16 \%$ drop from Scenario III and 59.12\% reduction from Scenario I. In comparison to Scenario III, the cost of pumping decreased slightly from $0.5 € / \mathrm{h}$ to $0.48 € / \mathrm{h}$. The electricity distribution losses also decreased slightly from $0.85 \mathrm{~kW}$ to $0.84 \mathrm{~kW}$. The total 
operating cost in Scenario IV is $69.26 € / \mathrm{h}$ showing a $0.4 \%$ decrease from Scenario III and about $9.37 \%$ reduction from Scenario I.

Figure 5 presents the heat losses (on the left axis) and the operating costs (on the right axis) under different scenarios. It shows how much the operating cost and the total heat loss are progressively decreased and how much of the total loss is shared by each of the branches.

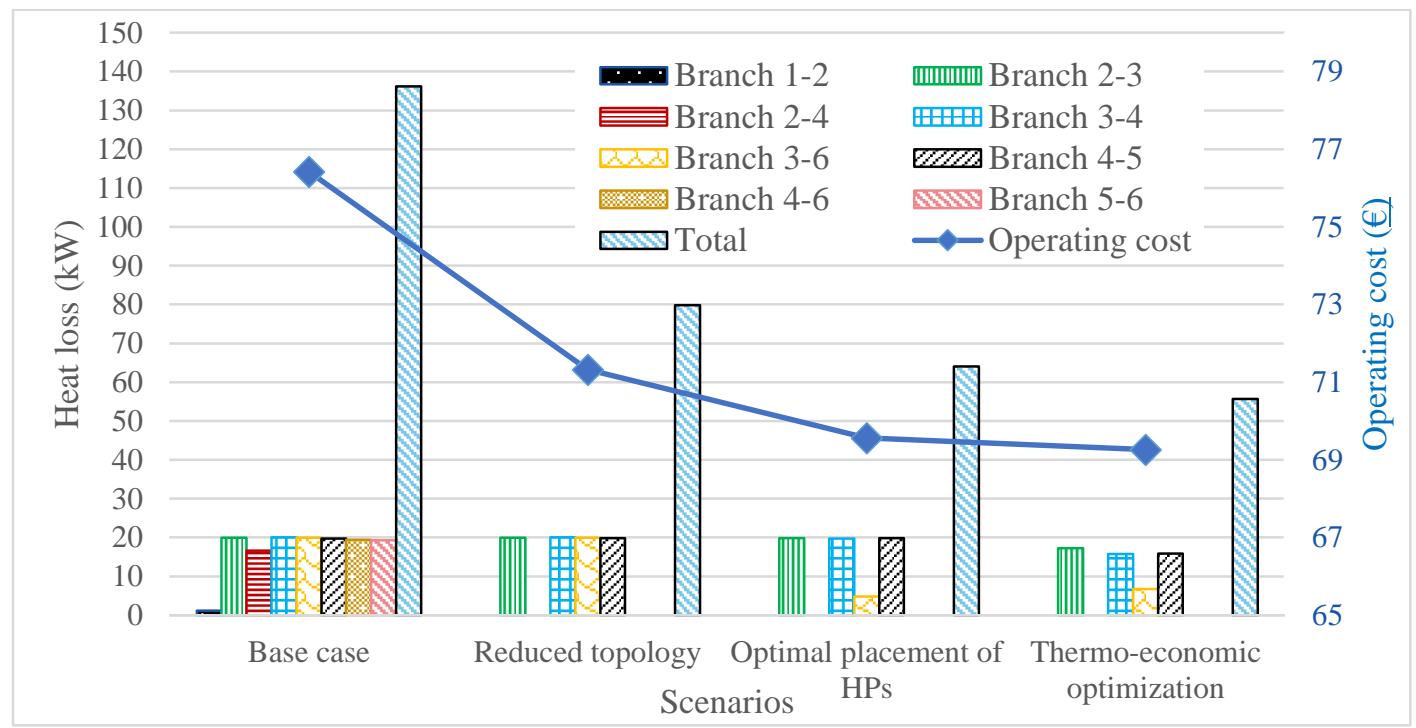

Fig. 5 Comparison of operating costs and heat losses at different operating scenarios.

\subsection{Computational efforts}

All the simulations are done on MatlabR2017a platform running on a Dell desktop computer with Intel Core i5-8400CPU processor $(2.80 \mathrm{GHz}$ and $2.81 \mathrm{GHz})$ with a 64bit Windows 10 Operating system. Each of the simulations are repeated 10 times. Although the results were very close to each other, all the discussions are based on the best values obtained. The load flow simulations are completed in fractions of seconds. The optimal power flow simulations (Scenarios I and II) took between 95 - 187 seconds. The thermo-economic optimisation (Scenario IV) needed $137-275$ seconds to finish due to larger population size used in the PSO. The optimal placement of HPs (Scenario III), on the other hand, took between 860 - 1040 seconds.

The simulation time step considered is one hour and all of the simulations were completed in a much shorter time. Furthermore, the optimal placement algorithm is supposed to be run only once to find best placement for the HPs. In that regard, the time it takes can be ignored. However, these numbers are rough figures and vary with the network size and operating condition of the computer. They are meant only to give an idea how the simulations can be used in a real time application. It can be said that the methodology and algorithms developed in this paper can be run on ordinary desktop computer and are suitable for small to medium size district energy system simulations running on hourly bases.

\section{Conclusions}

A step-by-step approach of applying energy and exergy analyses on the distribution pipes and nodes of a DHN is presented in this paper together with an optimal placement of coupling technologies such as HPs. The network topology optimisation based on branch efficiency showed that both of the energy and exergy analyses result in the same reduced network topology. However, the exergy analysis is found to be straightforward giving a better clarity in identifying the lossy branches and nodes in the DHN. Significant amount of exergy destruction takes place across the branches, rather than at the nodes. It has also been found that the contribution of the return pipe network in the exergy loss is not negligible, though it is much lower than the supply side pipe networks. 
After determining the optimal topology of the DHN, optimal placement of HPs is conducted using nested PSO technique. The optimisation results show that the location of HPs also has an impact on both distribution loss and cost of pumping. The thermo-economic optimisation further revealed that lowering the supply temperature does not necessarily result in a lower operational cost. The pumping cost may sometimes counter balance the advantages of lower supply temperatures. However, lowering the return temperature of the consumers (on the primary side) is found to be always economical.

Compared to the base case scenario, topology reduction resulted a reduction of $41.37 \%$ of the distribution heat loss while optimal placement of heat pumps and thermo-economic optimisation showed $52.93 \%$ and $59.12 \%$ loss reduction, respectively. Up to $9.37 \%$ saving on the total operating cost is also achieved.

The methodology presented in this paper can be extended by considering various technologies in a multi energy system. For example, the exergy analysis covered in this study is limited to the distribution branches and nodes of the DHN. It can be complemented by considering the exergy interaction between different energy carriers inside the energy hubs, such as HPs, CHPs and substations. The COP of each HP is also assumed to be constant for partial and full load operation. This could be improved by incorporating efficiency curves of HPs. Electricity demands with both active and reactive loads together with CHPs and HPs with lagging power factors can also be considered to study the capacity of the electricity distribution network. The sensitivity of the optimal solutions can also be further investigated by considering a range of prices for different energy carriers, such as gas, fuel, electricity and heat. A pseudo-dynamic simulation can also be incorporated by considering time series load profiles, thermal storage and wind power generation forecast. Optimisation algorithms other than PSO can also be applied for comparative study.

\section{Acknowledgments}

The research presented is performed within the framework of the Erasmus Mundus Joint Doctorate SELECT+ program 'Environomical Pathways for Sustainable Energy Services' and funded with support from the Education, Audiovisual, and Culture Executive Agency (EACEA) (FPA-20120034) of the European Commission. This publication reflects the views only of the author(s), and the Commission cannot be held responsible for any use, which may be made of the information contained therein.

\section{Nomenclatures}

$\begin{array}{ll}\mathrm{B} & \begin{array}{l}\text { Susceptance of transmission line } \\ (\mathrm{S})\end{array} \\ \mathrm{B}_{\mathrm{ph}} & \text { Physical exergy (W) } \\ c_{1} & \text { Personal acceleration factor } \\ c_{2} & \text { Global acceleration factor } \\ \mathrm{C}_{\mathrm{p}} & \text { Specific heat capacity of water } \\ & \text { (J/kg.K) } \\ \text { CHP } & \text { Combined heat and power } \\ \text { CHP Pepg } & \text { Active electrical power } \\ \text { CHP Phg } & \text { produced by the CHP (W) } \\ \text { COP } & \text { CHP (W) produced from the } \\ \text { D, D } & \text { Coefficient of performance } \\ \text { D3 } & \text { Internal diameter of a pipe (m) } \\ \text { DHN } & \text { Outer diameter of insulating } \\ & \text { material(m) } \\ & \text { District Heating Network }\end{array}$


e

$\mathrm{H}$

HP

HP Lep

HP Phg

K

L

$\mathrm{L}_{\mathrm{h}}$

$\dot{m}$

$\dot{m}_{i j}$

MES

$\mathrm{P}_{\mathrm{el}}$

$\mathrm{P}_{\text {elg }}$

$\mathrm{P}_{\mathrm{h}}$

$\mathrm{P}_{\text {hg }}$

$\mathrm{P}$

$\mathrm{P}_{\mathrm{o}}$

PSO

Qel

Qelg

R

$\mathrm{T}$

$\mathrm{t}_{1}$

$t_{3}$

$\mathrm{T}_{\mathrm{o}}$

V

$v_{i-n e w}$

$v_{i o}$

$\mathrm{W}_{\mathrm{e}}$

X

$x_{i}$

$x_{i-n e w}$

$x_{i-b e s t}$

$x_{g-\text { best }}$

$\omega$

\section{Subscripts}
$\mathrm{i}, \mathrm{j}, \mathrm{k}$
$\mathrm{r}$
s
Hub numbers
Return pipe of DHN
Supply pipe of DHN

Internal surface roughness of a pipe (m)

Hydraulic head (m)

Heat pump

Electricity consumption of HP (W)

Heat power produced by the HP (W)

Pressure resistance coefficient (m. $\mathrm{s}^{2} / \mathrm{kg}^{2}$ )

Length ( $m$ )

Heat power demand (W)

Mass flow rate from a hub $(\mathrm{kg} / \mathrm{s})$

Mass flow rate from node $\mathrm{i}$ to $\mathrm{j}$

(kg/s)

Multi-energy system

Active electric power injection

(W)

Active electric power generated

(W)

Heat power injection (W)

Heat power generated (W)

Pressure of water $(\mathrm{Pa})$

Reference pressure $(\mathrm{Pa})$

Particle Swarm Optimisation

Reactive power injection (var)

Reactive power generated (var)

Resistance of a transmission line

$(\Omega)$

Temperature (K)

Thickness of carrier pipe (m)

Thickness of outer jacket (m)

Reference temperature $(\mathrm{K})$

voltage (V)

new velocity of particle $i$

current velocity of particle $i$

electricity used for circulation pumps (W)

Reactance of a transmission line

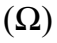

current position of particle $i$

new position of particle $i$

Best position of particle $i$

Global best position

inertia factor 


\section{Appendices}

\section{A: Branch parameters}

Table A.1: Pipe and transmission line parameters.

\begin{tabular}{|l|c|c|c|c|c|c|c|c|c|c|c|c|c|c|}
\hline \multicolumn{3}{|l}{ Hubs } & \multicolumn{4}{|c|}{ Carrier Pipe Parameters } & \multicolumn{2}{c|}{ Insulation } & \multicolumn{3}{c|}{ Outer Jacket } & \multicolumn{2}{l|}{ Transmission lines } \\
\hline from & $\mathrm{to}$ & $\begin{array}{c}\mathrm{L} \\
(\mathrm{m})\end{array}$ & $\begin{array}{c}\mathrm{D}_{1}+\mathrm{t}_{1} \\
(\mathrm{~mm})\end{array}$ & $\begin{array}{c}\mathrm{t}_{1} \\
(\mathrm{~mm})\end{array}$ & $\begin{array}{c}\mathrm{k}_{2} \\
(\mathrm{~W} / \mathrm{mK})\end{array}$ & $\begin{array}{c}\mathrm{e} \\
(\mathrm{mm})\end{array}$ & $\begin{array}{c}\mathrm{k}_{3} \\
(\mathrm{~W} / \mathrm{mK})\end{array}$ & $\begin{array}{c}\mathrm{D}_{3} \\
(\mathrm{~mm})\end{array}$ & $\begin{array}{c}\mathrm{t}_{3} \\
(\mathrm{~mm})\end{array}$ & $\begin{array}{c}\mathrm{k}_{4} \\
(\mathrm{~W} / \mathrm{mK})\end{array}$ & $\begin{array}{c}\mathrm{L} \\
(\mathrm{km})\end{array}$ & $\begin{array}{c}\mathrm{R} \\
(\Omega / \mathrm{km})\end{array}$ & $\begin{array}{c}\mathrm{X} \\
(\Omega / \mathrm{km})\end{array}$ & $\begin{array}{c}\mathrm{B} \\
(\mu \mathrm{S} / \mathrm{km})\end{array}$ \\
\hline $\mathbf{1}$ & 2 & 50 & 60.3 & 3.2 & 40 & 0.05 & 0.027 & 125 & 3.0 & 0.40 & 0.05 & 0.262 & 0.386 & 4.31 \\
\hline $\mathbf{2}$ & 3 & 600 & 60.3 & 3.2 & 40 & 0.05 & 0.027 & 125 & 3.0 & 0.40 & 0.60 & 0.307 & 0.386 & 4.31 \\
\hline $\mathbf{2}$ & 4 & 600 & 60.3 & 3.2 & 40 & 0.05 & 0.027 & 125 & 3.0 & 0.40 & 0.60 & 0.307 & 0.386 & 4.31 \\
\hline $\mathbf{3}$ & 4 & 600 & 60.3 & 3.2 & 40 & 0.05 & 0.027 & 125 & 3.0 & 0.40 & 0.60 & 0.307 & 0.386 & 4.31 \\
\hline $\mathbf{3}$ & 6 & 600 & 60.3 & 3.2 & 40 & 0.05 & 0.027 & 125 & 3.0 & 0.40 & 0.60 & 0.307 & 0.386 & 4.31 \\
\hline $\mathbf{4}$ & 5 & 600 & 60.3 & 3.2 & 40 & 0.05 & 0.027 & 125 & 3.0 & 0.40 & 0.60 & 0.307 & 0.386 & 4.31 \\
\hline $\mathbf{4}$ & 6 & 600 & 60.3 & 3.2 & 40 & 0.05 & 0.027 & 125 & 3.0 & 0.40 & 0.60 & 0.307 & 0.386 & 4.31 \\
\hline $\mathbf{5}$ & 6 & 600 & 60.3 & 3.2 & 40 & 0.05 & 0.027 & 125 & 3.0 & 0.40 & 0.60 & 0.307 & 0.386 & 4.31 \\
\hline
\end{tabular}

\section{B. Intermediate results of topology reduction (Scenario II)}

Table B.1: Nodal results of the economic dispatch after isolating the $1^{\text {st }}$ lossy branch

\begin{tabular}{|c|c|c|c|c|c|c|c|c|c|c|c|c|}
\hline Hub & $\begin{array}{l}\text { Pepg } \\
(\mathbf{k W})\end{array}$ & $\begin{array}{c}\text { HP Lep } \\
(\mathrm{kW})\end{array}$ & $\begin{array}{c}\text { HP Phg } \\
(\mathbf{k W})\end{array}$ & \begin{tabular}{c|c} 
CHP Pepg \\
$(\mathbf{k W})$
\end{tabular} & $\begin{array}{c}\text { CHP Phg } \\
(\text { kW) }\end{array}$ & $\begin{array}{l}\text { Phg } \\
(\mathrm{kW})\end{array}$ & $\begin{array}{c}\text { Lh } \\
(\mathbf{k W})\end{array}$ & $\underset{(\mathrm{kg} / \mathrm{s})}{\dot{m}}$ & Ts $\left({ }^{\circ} \mathrm{C}\right)$ & $\operatorname{Tr}\left({ }^{\circ} \mathrm{C}\right)$ & $\begin{array}{l}\text { Hs } \\
(\mathbf{m})\end{array}$ & $\operatorname{Hr}(\mathbf{m})$ \\
\hline 1 & 0.00 & 0.00 & 0.00 & 0.00 & 0.00 & 26.53 & 0.00 & 2.88 & 41.89 & 39.69 & 30.00 & 30.00 \\
\hline 2 & 0.00 & 500.00 & 0.00 & 0.00 & 0.00 & 0.00 & 0.00 & -5.09 & 63.48 & 40.00 & 28.34 & 31.66 \\
\hline 3 & 0.00 & 200.00 & 1520.00 & 380.0 & 470.0 & 0.00 & 380.00 & 9.35 & 85.00 & 39.24 & 50.44 & 9.56 \\
\hline 4 & 0.00 & 1000.00 & 0.00 & 0.00 & 0.00 & 0.00 & 0.00 & -5.98 & 79.98 & 40.00 & 26.44 & 33.56 \\
\hline 5 & 125.0 & 200.00 & 500.00 & 0.00 & 0.00 & 0.00 & 125.00 & 1.56 & 85.00 & 38.98 & 32.63 & 27.37 \\
\hline 6 & 0.00 & 500.00 & 0.00 & 0.00 & 0.00 & 0.00 & 0.00 & -2.72 & 83.98 & 40.00 & 26.99 & 33.01 \\
\hline
\end{tabular}

Table B.2: Branch results of the economic dispatch after isolating the $1^{\text {st }}$ lossy branch.

\begin{tabular}{|r|c|r|r|r|r|}
\hline \multicolumn{2}{|c|}{ Hubs } & \multicolumn{4}{|c|}{ Branch i to j } \\
\hline $\mathbf{i}$ & $\mathrm{j}$ & $\begin{array}{c}\text { We(branch) } \\
(\mathrm{kW})\end{array}$ & $\begin{array}{c}\text { Net heat flow } \\
(\mathrm{kW})\end{array}$ & $\begin{array}{c}\text { Loss } \\
(\mathrm{kW})\end{array}$ & Energy efficiency \\
\hline 1 & 2 & 0.152 & 25.39 & 1.14 & $95.17 \%$ \\
\hline 2 & 3 & 2.141 & -562.47 & 19.95 & $96.22 \%$ \\
\hline 2 & 4 & 0.050 & 71.33 & 16.54 & $81.13 \%$ \\
\hline 3 & 4 & 2.427 & 584.18 & 20.00 & $96.30 \%$ \\
\hline 3 & 6 & 2.344 & 583.48 & 19.92 & $96.32 \%$ \\
\hline $\mathbf{4}$ & 5 & 0.307 & -280.12 & 19.88 & $93.28 \%$ \\
\hline $\mathbf{4}$ & 6 & 0.007 & -64.36 & 19.11 & $77.10 \%$ \\
\hline
\end{tabular}

Table B.3: Nodal results of the economic dispatch after isolating the $2^{\text {nd }}$ lossy branch.

\begin{tabular}{|c|c|c|c|c|c|c|c|c|c|c|c|c|}
\hline Hub & $\begin{array}{l}\text { Pepg } \\
(\mathbf{k W})\end{array}$ & $\begin{array}{c}\text { HP Lep } \\
(\mathbf{k W})\end{array}$ & $\begin{array}{c}\text { HP Phg } \\
(\mathbf{k W})\end{array}$ & $\begin{array}{c}\text { CHP Pepg } \\
(\mathbf{k W})\end{array}$ & $\begin{array}{c}\text { CHP Phg } \\
(\mathbf{k W})\end{array}$ & $\begin{array}{l}\text { Phg } \\
(\mathbf{k W})\end{array}$ & $\begin{array}{c}\mathbf{L h} \\
(\mathbf{k W})\end{array}$ & $\dot{m}(\mathrm{~kg} / \mathrm{s})$ & Ts $\left({ }^{\circ} \mathbf{C}\right)$ & $\operatorname{Tr}\left({ }^{\circ} \mathrm{C}\right)$ & Hs (m) & Hr (m) \\
\hline 1 & 0.0 & 0.00 & 0.0 & 0.00 & 0.00 & 7.57 & 0.0 & 2.80 & 40.34 & 39.69 & 30.00 & 30.00 \\
\hline 2 & 0.0 & 0.00 & 0.0 & 0.00 & 0.00 & 0.00 & 500.0 & -5.03 & 63.75 & 40.00 & 28.43 & 31.57 \\
\hline 3 & 0.0 & 380.00 & 1520.0 & 380.0 & 470.0 & 0.00 & 200.0 & 9.38 & 85.00 & 39.40 & 53.38 & 6.62 \\
\hline 4 & 0.0 & 0.00 & 0.0 & 0.00 & 0.00 & 0.00 & 1000.0 & -5.98 & 79.97 & 40.00 & 25.71 & 34.29 \\
\hline 5 & 125.0 & 125.00 & 500.0 & 0.00 & 0.00 & 0.00 & 200.0 & 1.56 & 85.00 & 38.98 & 31.90 & 28.10 \\
\hline 6 & 0.0 & 0.00 & 0.0 & 0.00 & 0.00 & 0.00 & 500.00 & -2.73 & 83.83 & 40.00 & 35.46 & 24.54 \\
\hline
\end{tabular}

Table B.4: Branch results of the economic dispatch after isolating the $2^{\text {nd }}$ lossy branch.

\begin{tabular}{|r|c|r|r|r|r|}
\hline \multicolumn{2}{|c|}{ Hubs } & \multicolumn{4}{|c|}{ Branch i to j } \\
\hline $\mathbf{i}$ & $\mathrm{j}$ & $\begin{array}{c}\text { We(branch) } \\
(\mathrm{kW})\end{array}$ & $\begin{array}{c}\text { Net heat flow } \\
(\mathrm{kW})\end{array}$ & $\begin{array}{c}\text { Loss } \\
(\mathrm{kW})\end{array}$ & Efficiency \\
\hline 1 & 2 & 0.140 & 6.46 & 1.12 & $83.70 \%$ \\
\hline 2 & 3 & 2.576 & -599.98 & 19.96 & $96.38 \%$ \\
\hline 2 & 4 & 0.087 & 89.79 & 16.64 & $84.30 \%$ \\
\hline 3 & 4 & 3.015 & 630.08 & 20.00 & $96.48 \%$ \\
\hline
\end{tabular}




\begin{tabular}{|l|l|r|r|r|r|}
\hline 3 & 6 & 1.558 & 500.00 & 19.98 & $95.87 \%$ \\
\hline $\mathbf{4}$ & 5 & 0.307 & -280.12 & 19.88 & $93.28 \%$ \\
\hline
\end{tabular}

Table B.5: Exergy of water at the inlet and outlet of branch pipes and associated losses after isolating the $1^{\text {st }}$ lossy branch.

\begin{tabular}{|c|c|c|c|c|c|c|c|c|}
\hline \multicolumn{2}{|c|}{ Hubs } & \multicolumn{2}{|c|}{ Exergy of pipe on the supply side (kW) } & \multicolumn{2}{|c|}{ Exergy of pipe on the return side $(\mathrm{kW})$} & \multicolumn{3}{|c|}{ Branch i to $\mathbf{j}$} \\
\hline $\mathbf{i}$ & $\mathrm{j}$ & At node $\mathrm{i}$ & At node $\mathrm{j}$ & At node $\mathrm{i}$ & At node $\mathrm{j}$ & $\begin{array}{l}\text { Net exergy } \\
\text { flow }(\mathrm{kW})\end{array}$ & Exergy lost (kW) & $\begin{array}{l}\text { Exergy } \\
\text { efficiency }\end{array}$ \\
\hline 1 & 2 & 44.84 & 44.71 & 40.97 & 41.10 & 85.68 & 0.41 & $99.52 \%$ \\
\hline 2 & 3 & 154.92 & 158.92 & 43.42 & 41.81 & 196.74 & 7.74 & $96.22 \%$ \\
\hline 2 & 4 & 26.10 & 24.09 & 11.03 & 11.97 & 35.11 & 3.00 & $92.12 \%$ \\
\hline 3 & 4 & 165.88 & 161.80 & 44.18 & 45.88 & 205.98 & 8.21 & $96.17 \%$ \\
\hline 3 & 6 & 163.90 & 159.85 & 42.74 & 44.40 & 202.59 & 8.06 & $96.18 \%$ \\
\hline 4 & 5 & 77.78 & 81.17 & 22.53 & 21.49 & 99.27 & 4.74 & $95.44 \%$ \\
\hline 4 & 6 & 18.28 & 21.34 & 6.05 & 5.16 & 23.44 & 3.97 & $85.52 \%$ \\
\hline
\end{tabular}

Table B.6: Exergy of water at the inlet and outlet of branch pipes and associated losses after isolating the $2^{\text {nd }}$ lossy branch.

\begin{tabular}{|c|c|c|c|c|c|c|c|c|}
\hline \multicolumn{2}{|c|}{ Node } & \multicolumn{2}{|c|}{ Exergy of pipe on the supply side (kW) } & \multicolumn{2}{|c|}{ Exergy of pipe on the return side (kW) } & \multicolumn{3}{|c|}{ Branch i to $\mathbf{j}$} \\
\hline $\mathbf{i}$ & $\mathrm{j}$ & At node i & At node $\mathrm{j}$ & At node $\mathrm{i}$ & At node $\mathrm{j}$ & $\begin{array}{l}\text { Net exergy } \\
\text { flow }(\mathrm{kW})\end{array}$ & Exergy lost $(\mathrm{kW})$ & $\begin{array}{l}\text { Exergy } \\
\text { efficiency }\end{array}$ \\
\hline 1 & 2 & 40.92 & 40.79 & 39.83 & 39.95 & 80.62 & 0.39 & $99.52 \%$ \\
\hline 2 & 3 & 165.25 & 169.38 & 46.25 & 44.52 & 209.77 & 8.44 & $96.13 \%$ \\
\hline 2 & 4 & 31.92 & 29.86 & 13.57 & 14.53 & 43.44 & 3.10 & $93.34 \%$ \\
\hline 3 & 4 & 178.72 & 174.46 & 47.55 & 49.43 & 222.01 & 9.16 & $96.04 \%$ \\
\hline 3 & 6 & 142.59 & 138.77 & 37.74 & 39.18 & 176.52 & 6.80 & $96.29 \%$ \\
\hline 4 & 5 & 77.77 & 81.16 & 22.54 & 21.50 & 99.27 & 4.74 & $95.44 \%$ \\
\hline
\end{tabular}

\section{References}

Aote, S.S., Raghuwanshi, M.M., Malik, L.G., 2016. Improved Particle Swarm Optimisation Based on Natural Flocking Behavior. Arab J Sci Eng 41, 1067-1076. https://doi.org/10.1007/s13369-015-1990-5

Attous, D.B., Labbi, Y., 2009. Particle swarm optimisation based optimal power flow for units with non-smooth fuel cost functions, in: International Conference on Electrical and Electronics Engineering, 2009. ELECO 2009. Presented at the International Conference on Electrical and Electronics Engineering, 2009. ELECO 2009, pp. I-377-I-381. https://doi.org/10.1109/ELECO.2009.5355329

Ayele, G.T., Haurant, P., Laumert, B., Lacarrière, B., 2018a. An extended energy hub approach for load flow analysis of highly coupled district energy networks: Illustration with electricity and heating. Applied Energy 212, 850-867. https://doi.org/10.1016/j.apenergy.2017.12.090

Ayele, G.T., Mabrouk, M.T., Haurant, P., Laumert, B., Lacarrière, B., 2019. Optimal placement and sizing of heat pumps and heat only boilers in a coupled electricity and heating networks. Energy 182, 122-134. https://doi.org/10.1016/j.energy.2019.06.018

Ayele, G.T., Mabrouk, M.T., Haurant, P., Laumert, B., Lacarrière, B., 2018b. Pseudo-dynamic simulation on a district energy system made of coupling technologies, in: ECOS 2018 - 31st International Conference on Efficiency, Cost, Optimisation, Simulation and Environmental Impact of Energy Systems. Guimaraes, Portugal.

Bejan, A., Bejan, Moran, Tsatsaronis, G., Moran, M., Moran, M.J., Moran, P. of G. and a M. of C.M., 1996. Thermal Design and Optimisation. John Wiley \& Sons. 
Bergman, T.L., Incropera, F.P., DeWitt, D.P., Lavine, A.S., 2011. Fundamentals of heat and mass transfer. John Wiley \& Sons.

Beuzekom, I. van, Gibescu, M., Slootweg, J.G., 2015. A review of multi-energy system planning and optimisation tools for sustainable urban development, in: 2015 IEEE Eindhoven PowerTech. Presented at the 2015 IEEE Eindhoven PowerTech, pp. 1-7. https://doi.org/10.1109/PTC.2015.7232360

Bilgen, E., Takahashi, H., 2002. Exergy analysis and experimental study of heat pump systems. Exergy, An International Journal 2, 259-265. https://doi.org/10.1016/S1164-0235(02)000833

Caliskan, H., 2014. Energy, exergy, thermoeconomic and sustainability analyses of a building heating system with a combi-boiler. International Journal of Exergy 14, 244-273. https://doi.org/10.1504/IJEX.2014.060282

Campos Celador, A., Erkoreka, A., Martin Escudero, K., Sala, J.M., 2011. Feasibility of small-scale gas engine-based residential cogeneration in Spain. Energy Policy 39, 3813-3821. https://doi.org/10.1016/j.enpol.2011.04.011

Compton, M., Rezaie, B., Rosen, M.A., 2018. Exergy approach for advancing sustainability of a biomass boiler. International Journal of Exergy 27, 62-80. https://doi.org/10.1504/IJEX.2018.093900

Coskun, C., Oktay, Z., Dincer, I., 2010. Investigation of some renewable energy and exergy parameters for two Geothermal District Heating Systems. International Journal of Exergy 8, 1-15. https://doi.org/10.1504/IJEX.2011.037211

Coss, S., Guelpa, E., Letournel, E., Le-Corre, O., Verda, V., Coss, S., Guelpa, E., Letournel, E., LeCorre, O., Verda, V., 2017. Formulation of Exergy Cost Analysis to Graph-Based Thermal Network Models. Entropy 19, 109. https://doi.org/10.3390/e19030109

Curti, V., von Spakovsky, M.R., Favrat, D., 2000. An environomic approach for the modeling and optimisation of a district heating network based on centralized and decentralized heat pumps, cogeneration and/or gas furnace. Part I: Methodology. International Journal of Thermal Sciences 39, 721-730. https://doi.org/10.1016/S1290-0729(00)00226-X

Dincer, I., Rosen, M.A., 2013. Exergy: Energy, Environment and Sustainable Development, Second Edition. ed. Elsevier. https://doi.org/10.1016/B978-0-08-097089-9.00002-4

European Commission, 2015. Heating and cooling [WWW Document]. Energy - European Commission. URL https://ec.europa.eu/energy/en/topics/energy-efficiency/heating-andcooling (accessed 11.20.19).

Eurostat, 2018. Energy for heating / cooling from renewable sources [WWW Document]. URL https://ec.europa.eu/eurostat/web/products-eurostat-news/-/DDN-20190304-1 (accessed 11.20.19).

Frederiksen, S., Werner, S., 2013. District Heating and Cooling. Studentlitteratur AB.

Glover, J.D., Sarma, M.S., Overbye, T., 2012. Power System Analysis \& Design, SI Version. Cengage Learning.

Hazra, J., Sinha, A.K., 2011. A multi-objective optimal power flow using particle swarm optimisation. European Transactions on Electrical Power 21, 1028-1045. https://doi.org/10.1002/etep.494

HOMER Energy, n.d. HOMER - Hybrid Renewable and Distributed Generation System Design Software [WWW Document]. URL https://www.homerenergy.com/ (accessed 11.5.18).

Isoplus, n.d. isoplus: Flexible and rigid pipes and pipeline systems: isoplus - isoplus Fernwärmetechnik [WWW Document]. URL http://www.isoplus-pipes.com/ (accessed 9.3.17).

Juneja, M., Nagar, S.K., 2016. Particle swarm optimisation algorithm and its parameters: A review, in: 2016 International Conference on Control, Computing, Communication and Materials (ICCCCM). Presented at the 2016 International Conference on Control, Computing, Communication and Materials https://doi.org/10.1109/ICCCCM.2016.7918233

(ICCCCM), pp. 1-5. 
Kennedy, J., Eberhart, R., 1995. Particle swarm optimisation, in: Proceedings of ICNN'95 International Conference on Neural Networks. Presented at the Proceedings of ICNN'95 International Conference on Neural Networks, pp. 1942-1948 vol.4. https://doi.org/10.1109/ICNN.1995.488968

Kontu, K., Rinne, S., Junnila, S., 2019. Introducing modern heat pumps to existing district heating systems - Global lessons from viable decarbonizing of district heating in Finland. Energy 166, 862-870. https://doi.org/10.1016/j.energy.2018.10.077

Levihn, F., 2017. CHP and heat pumps to balance renewable power production: Lessons from the district heating network in Stockholm. Energy. https://doi.org/10.1016/j.energy.2017.01.118

Li, H., Svendsen, S., 2012. Energy and exergy analysis of low temperature district heating network. Energy, The 24th International Conference on Efficiency, Cost, Optimisation, Simulation and Environmental Impact of Energy, ECOS 2011 45, 237-246. https://doi.org/10.1016/j.energy.2012.03.056

Lund, H., Werner, S., Wiltshire, R., Svendsen, S., Thorsen, J.E., Hvelplund, F., Mathiesen, B.V., 2014. 4th Generation District Heating (4GDH): Integrating smart thermal grids into future sustainable energy systems. Energy 68, 1-11. https://doi.org/10.1016/j.energy.2014.02.089

Mazairac, W., Salenbien, R., Vries, B. de, 2015. Mixed-integer linear program for an optimal hybrid energy network topology, in: 2015 International Conference on Renewable Energy Research and Applications (ICRERA). Presented at the 2015 International Conference on Renewable Energy Research and Applications (ICRERA), pp. 861-866. https://doi.org/10.1109/ICRERA.2015.7418533

Natural Resources Canada, 2010. RETScreen [WWW Document]. URL https://www.nrcan.gc.ca/energy/software-tools/7465 (accessed 11.5.18).

Nemati, M., Braun, M., Tenbohlen, S., 2018. Optimisation of unit commitment and economic dispatch in microgrids based on genetic algorithm and mixed integer linear programming. Applied Energy 210, 944-963. https://doi.org/10.1016/j.apenergy.2017.07.007

Niknam, T., Azizipanah-Abarghooee, R., Aghaei, J., 2013. A new modified teaching-learning algorithm for reserve constrained dynamic economic dispatch. IEEE Transactions on Power Systems 28, 749-763. https://doi.org/10.1109/TPWRS.2012.2208273

Niknam, T., Narimani, M.R., Aghaei, J., Tabatabaei, S., Nayeripour, M., 2011. Modified Honey Bee Mating Optimisation to solve dynamic optimal power flow considering generator constraints. Transmission Distribution IET Generation 5, 989-1002. https://doi.org/10.1049/ietgtd.2011.0055

Ozgener, L., Hepbasli, A., Dincer, I., 2005. Thermodynamic analysis of a geothermal district heating system. International Journal of Exergy 2, 231-245. https://doi.org/10.1504/IJEX.2005.007246

Park, B.-S., Imran, M., Hoon, I.-Y., Usman, M., 2017. Thermo-economic optimisation of secondary distribution network of low temperature district heating network under local conditions of South Korea. Applied Thermal Engineering 126, 117-133. https://doi.org/10.1016/j.applthermaleng.2017.07.080

Pompei, L., Nardecchia, F., Mattoni, B., Gugliermetti, L., Bisegna, F., 2019. Combining the exergy and energy analysis for the assessment of district heating powered by renewable sources, in: 2019 IEEE International Conference on Environment and Electrical Engineering and 2019 IEEE Industrial and Commercial Power Systems Europe (EEEIC / I CPS Europe). Presented at the 2019 IEEE International Conference on Environment and Electrical Engineering and 2019 IEEE Industrial and Commercial Power Systems Europe (EEEIC / I CPS Europe), pp. 1-5. https://doi.org/10.1109/EEEIC.2019.8783426

PowerWorld, n.d. The visual approach to electric power systems [WWW Document]. URL https://www.powerworld.com/ (accessed 11.14.18).

Ratlamwala, T.A.H., Ali, S.I., Riaz, A., Hamza, S.M., 2019. Municipal solid waste based multigeneration system for different districts of Karachi. International Journal of Exergy 29, 300-317. https://doi.org/10.1504/IJEX.2019.100368 
Shabanpour-Haghighi, A., Seifi, A.R., Niknam, T., 2014. A modified teaching-learning based optimisation for multi-objective optimal power flow problem. Energy Conversion and Management 77, 597-607. https://doi.org/10.1016/j.enconman.2013.09.028

Subbaraj, P., Rengaraj, R., Salivahanan, S., 2009. Enhancement of combined heat and power economic dispatch using self adaptive real-coded genetic algorithm. Applied Energy 86, 915921. https://doi.org/10.1016/j.apenergy.2008.10.002

Terehovics, E., Veidenbergs, I., Blumberga, D., 2017. Exergy Analysis for District Heating Network. Energy Procedia, International Scientific Conference "Environmental and Climate Technologies", CONECT 2016, 12-14 October 2016, Riga, Latvia 113, 189-193. https://doi.org/10.1016/j.egypro.2017.04.053

Tian, Z., Perers, B., Furbo, S., Fan, J., 2018. Thermo-economic optimisation of a hybrid solar district heating plant with flat plate collectors and parabolic trough collectors in series. Energy Conversion and Management 165, 92-101. https://doi.org/10.1016/j.enconman.2018.03.034

Tontu, M., Bilgili, M., Sahin, B., 2018. Performance analysis of an industrial steam power plant with varying loads. International Journal of Exergy 27, 231-250. https://doi.org/10.1504/IJEX.2018.094596

Ullmann, M.R.D., Pimentel, K.F., de Melo, L.A., da Cruz, G., Vinhal, C., 2017. Comparison of PSO variants applied to large scale optimisation problems, in: 2017 IEEE Latin American Conference on Computational Intelligence (LA-CCI). Presented at the 2017 IEEE Latin American Conference on Computational Intelligence (LA-CCI), pp. 1-6. https://doi.org/10.1109/LA-CCI.2017.8285728

Wang, H., Duanmu, L., Li, X., Lahdelma, R., 2017. Optimizing the District Heating Primary Network from the Perspective of Economic-Specific Pressure Loss. Energies 10, 1095. https://doi.org/10.3390/en10081095

Wang, J., Lu, Y., Yang, Y., Mao, T., 2016. Thermodynamic performance analysis and optimisation of a solar-assisted combined cooling, heating and power system. Energy 115, Part 1, 49-59. https://doi.org/10.1016/j.energy.2016.08.102

Wang, W., Wu, F., 2017. Exergy destruction analysis of heat exchanger in waste heat recovery system in Kroll process. International Journal of Exergy 22, 89-101. https://doi.org/10.1504/IJEX.2017.081204

Wang, Y., Zhang, N., Zhuo, Z., Kang, C., Kirschen, D., 2018. Mixed-integer linear programmingbased optimal configuration planning for energy hub: Starting from scratch. Applied Energy 210, 1141-1150. https://doi.org/10.1016/j.apenergy.2017.08.114

Werner, S., 2017. District heating and cooling in Sweden. Energy 126, 419-429. https://doi.org/10.1016/j.energy.2017.03.052

Yao, E., Wang, H., Wang, L., Xi, G., Maréchal, F., 2016. Thermo-economic optimisation of a combined cooling, heating and power system based on small-scale compressed air energy storage. Energy Conversion and Management 118, 377-386. https://doi.org/10.1016/j.enconman.2016.03.087

Zeng, J., Han, J., Zhang, G., 2016. Diameter optimisation of district heating and cooling piping network based on hourly load. Applied Thermal Engineering 107, 750-757. https://doi.org/10.1016/j.applthermaleng.2016.07.037

Zhang, H., Zhou, L., Huang, X., Zhang, X., 2019. Decarbonizing a large City's heating system using heat pumps: A case study of Beijing. Energy 186, 115820. https://doi.org/10.1016/j.energy.2019.07.150 